\title{
Sol-Gel Biotemplating Route with Cellulose Nanocrystals to Design Photocatalyst Boosting the Hydrogen Generation
}

\author{
Cong Wang, ${ }^{a}$ Jian Li, ${ }^{a}$ Erwan Paineau, ${ }^{\mathrm{b}}$ Abdelghani Laachachi, ${ }^{\mathrm{c}}$ Christophe Colbeau-Justin, ${ }^{a}$ Hynd \\ Remita $^{\text {add }}$ and Mohamed Nawfal Ghazzal*a \\ Light harvesting capability and charge carriers lifetime play critical roles in determining the photoefficency of photocatalyst. \\ Herein, a one-pot method is proposed to design mesostructured $\mathrm{TiO}_{2}$ materials by taking advantage of the ability of cellulose \\ nanocrystals (CNC) to self-assemble into chiral nematic structures during solvent evaporation. After the xerogel formation, \\ the as-obtained $\mathrm{CNC} / \mathrm{TiO}_{2}$ hybrid films exhibit a chiral nematic structure and tunable Bragg peak reflection, generating \\ lamellar $\mathrm{TiO}_{2}$ mesostructure after the biotemplate removal by calcination. More prominently, this straightforward method \\ can be extended to couple $\mathrm{TiO}_{2}$ with other metal oxides, improving the light-harvesting and charge carriers separation of \\ these photocatalysts, in particular for boosting hydrogen generation. This foolproof approach opens new doors for the \\ development of nanostructured materials for solar energy conversion and catalysis.
}

\section{Introduction}

Known as the bottleneck for the solar energy conversion efficiency, the capability of light harvesting and the separation of photogenerated charge carriers have attracted great interest. ${ }^{1}$ Structuring photoactive materials into photonic crystals or hierarchical structures are promising approaches for improving the efficiency of photoactive materials. A photonic crystal can be used either as a reflector element separated to the photoactive layer for light accumulation, ${ }^{2-4}$ or as a photoactive absorber to slow down the velocity of light. ${ }^{5,6}$ Hierarchical structures, like in green leaves, can improve light scattering for optimal light management toward an efficient conversion of photons into chemical energy. ${ }^{7}$ In this context, structuring inorganic materials at the mesoscale using selfbiotemplate assembly process appears as a sustainable method for the synthesis of functional material. Notably, cellulose nanocrystals (CNC, as a biotemplate) have the specificity of forming a chiral nematic (CN) structure, which can be replicated into inorganic materials, a structure never achieved before with classical aqueous sol-gel approaches using surfactants as templates. ${ }^{8,9}$ Freestanding silica films with $\mathrm{CN}$ structure were obtained by the polycondensation of tetraethyl orthosilane or methyl triethoxisilane precursors dissolved in CNC aqueous solution. ${ }^{10,11}$ This breakthrough has generated promises for the development of functional materials and the design of novel photonic crystals. However, the method is restricted only to mesoporous silica or organosilica films, which limits the application to the sensing and separation of chiral molecules. ${ }^{12,13}$ This limitation stems from the high sensitivity of the other precursors (metal chloride or alkoxides) to moisture leading to their fast hydrolysis and condensation, disorganizing the stability of chiral nematic structure of CNC into isotropic phase. Acid catalysis in sol-gel process is one way for stabilizing titania precursors in an aqueous solution containing CNC by promoting slow polycondensation but with the expense of limited hydrolysis. ${ }^{14-16}$ These infructuous attempts turn to colorless mesoporous $\mathrm{TiO}_{2}$ film where the $\mathrm{CN}$ structures of $\mathrm{CNC}$ are completely lost. The $\mathrm{CN}$ organization of $\mathrm{CNC}$ is very sensitive to the solvent polarity, ionic strength and $\mathrm{pH}$ of the aqueous solution. ${ }^{17}$ Other alternatives, such as hard templating or impregnation methods, have been proposed to transfer the helical structure into titanium dioxide films. ${ }^{18-20}$ Despite their efficiency and versatility, all these methods require multistep impregnation/drying to get the final material. Recently, a successful self-assembly of $\mathrm{CNC} / \mathrm{TiO}_{2}$ was proposed. ${ }^{21}$ The procedure requires complex steps to dissolve $\mathrm{TiO}_{2}$ nanoparticles and use sodium titanate precursor (unsuitable for photocatalysis or dye sensitized solar cells) to elaborate a water-soluble peroxotitante in CNC aqueous solution. The remaining sodium ion is known to have a detrimental effect on the photoefficiency of $\mathrm{TiO}_{2}$, as it acts as a recombination center for the photogenerated charge carriers. ${ }^{22,23}$ Clearly, it is challenging and highly desirable to develop an effective yet simple one-pot sol-gel self-biotemplating approach that can be extended to $\mathrm{TiO}_{2}$ and other functional metal oxides.

Here, we propose a straightforward one-pot method enabling both the structural design of $\mathrm{TiO}_{2}$ film and the coupling with metal oxides to improve the photon conversion efficiency. The one-pot self-biotemplating sol-gel approach enables the synthesis of $\mathrm{CNC} / \mathrm{TiO}_{2}$ and $\mathrm{CNC} /$ mixed oxides hybrid films with tunable Bragg peak reflection. A stable mixture of titanium diisopropoxide bis(acetylacetonate) (TAA) and an aqueous solution of CNC were used for the elaboration of the films. After removing the $\mathrm{CNC}$ biotemplate, the final $\mathrm{TiO}_{2}$ films exhibit a birefringent lamellar structure producing an increase of the photogenerated charge carriers lifetime. The assessment of charge carriers lifetime and the photocatalytic activity for hydrogen production were found to be significantly improved, compared to commercial $\mathrm{TiO}_{2}-\mathrm{P} 25$ (employed here as an internal standard). To validate the reliability and universality of our method, the procedure was extended to $\mathrm{TiO}_{2}$ mixed with different metal oxides $(\mathrm{Cu}, \mathrm{Ni}, \mathrm{Bi}, \mathrm{V})$ to increase the charge carriers separation, boosting the photocatalytic efficiency for hydrogen generation. 


\section{Experimental section}

\subsection{Synthesis of mesoporous lamellar $\mathrm{TiO}_{2}$ films}

A CNC aqueous suspension ( $10 \mathrm{~mL}, 4.0 \mathrm{wt} . \%, \mathrm{pH}=6.3$ ) was sonicated for $1 \mathrm{~h}$. Different volumes of TAA solutions (Table $\mathrm{S} 1 \dagger$ ) were added in $2 \mathrm{~mL}$ ethanol stirred for $10 \mathrm{~min}$, then the ethanolic TAA solutions were mixed with sonicated CNC suspension. After a slight shaking and stirring for $1 \mathrm{~h}$ giving homogeneous bright yellow mixtures, hereafter, poured into 55 $\mathrm{mm}$ diameter polystyrene Petri dishes and dried under room temperature for about $48 \mathrm{~h}$ to obtain iridescent $\mathrm{CNC} / \mathrm{TiO}_{2}$ hybrid films. The resulting hybrid films were then calcined in air at a heating rate of $1{ }^{\circ} \mathrm{C} / \mathrm{min}$ to $500{ }^{\circ} \mathrm{C}$ for $2 \mathrm{~h}$ and naturally cooled to room temperature yielding white mesoporous lamellar $\mathrm{TiO}_{2}$ films.

\subsection{Synthesis of mixed oxides films with lamellar structure}

A same CNC aqueous suspension was sonicated for $1 \mathrm{~h} .1 \mathrm{mg}$ of copper(II) acetate or nickel(II) acetylacetonate were added to 1 $\mathrm{mL}$ ethanol (in the case of bismuth(III) nitrate and vanadium(V) oxide, they were dissolved in deionized water) sonicated until clear solutions were obtained. $0.2 \mathrm{~mL}$ TAA solution was added in $1 \mathrm{~mL}$ ethanol stirred for $10 \mathrm{~min}$, then mixed with metal oxide solutions already prepared and stirred for another $10 \mathrm{~min}$. Then, the solution containing the precursors is added to the CNC suspension and stirred for $1 \mathrm{~h}$. The mixtures were poured into polystyrene Petri dishes to form the hybrid films. Finally, The same calcination procedure as detailed above is performed.

\section{Results and Discussion}

The ester sulfated surface of $\mathrm{CNC}\left(\mathrm{CNC}-\mathrm{OSO}_{3} \mathrm{H}\right)$ ensures the stability of the nanorods by electrostatic repulsion in aqueous suspensions. The ability of the negatively charged CNC nanorods to form CN phases relies on several parameters, such as the concentration of sulfate groups, the volume fraction of $\mathrm{CNC}$ and the $\mathrm{pH}$ of the medium..$^{24,25} 4 \mathrm{wt}$. \% CNC is the critical concentration corresponding to the onset of isotropic to chiral nematic phase transition. ${ }^{26}$ The cross-polarized optical microscopy (POM) image of this solution is shown in Fig. 1a. At this concentration, the suspension is weakly birefringent and tactoids (liquid crystalline droplets) with different sizes and shapes dispersed in a continuous isotropic phase have been observed (Fig. 1c). The Fig. 1c shows the typical POM (polarized optical microscopy) image of the CNC suspension containing tactoids with spherical and ellipsoidal shapes. These tactoids are considered as the primitive components of liquid crystals. They have parallel birefringent bands, similar to the chiral nematic structure observed for bulk CNC suspension (Fig. 1d). Tactoids spontaneously merge with each other and form the iridescent chiral nematic structure in the films. ${ }^{26}$ Both the CNC and hybrid TAA/CNC suspensions exhibit non-persistent strong shear-induced polychromatic birefringence between crossed polarizers, related to pretransitional effects (Fig. 1a and $b)$.
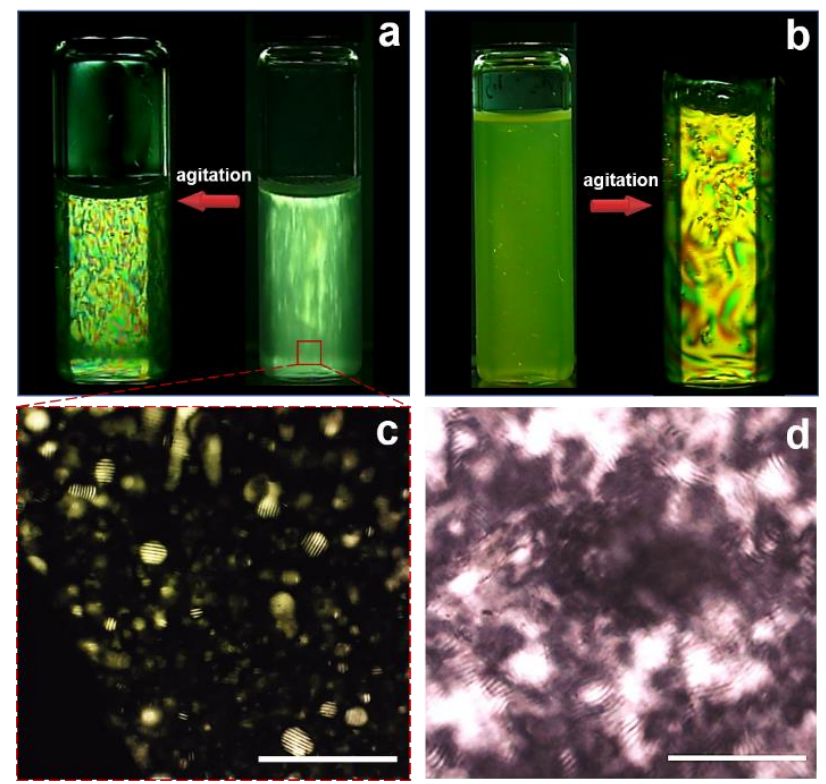

Fig. 1 Photographs of (a) pure CNC and (b) TAA/CNC (weight ratio=0.5) suspensions observed between crossed poalrizers before and during agitation (shear-induced polychromatic birefringence). Typical POM images of (c) CNC and (d) TAA/CNC suspensions during slow evaporation at room temperature (scale bar $=50 \mu \mathrm{m}$ ).

$\mathrm{CNC} / \mathrm{TiO}_{2}$ hybrid mesostructured films are prepared by evaporation induced self-assembly (EISA) of the solution containing the ethanolic solution of the $\mathrm{Ti}(\mathrm{acac})_{2} \mathrm{OiPr}_{2}$ precursor (TAA) and $\mathrm{CNC}$ suspension ( 4 wt.\%). The mixture is highly miscible after agitation, and a stable water-based $\mathrm{TiO}_{2}$-precursor solution (yellow and transparent) can easily be obtained (Fig. 1b). However, the solution does not show any birefringence, indicating isotropic phase transition due to the dilution induced by the addition of the precursor. In the TAA precursor, acetylacetonate acts as a chelating agent, which limits the precursors' reactivity towards hydrolysis and polycondensation, making the solution stable enough during the EISA process. The $\mathrm{pH}$ of the hybrid solution varies from 6.26 to 6.04 when the TAA ratio increases from 0.5 to 2.5 , corresponding to the initial pH of the CNC suspension $(\mathrm{pH}=6.3)$. Droplets evaporation of the TAA/CNC hybrid suspensions observe using POM are presented in Fig. $1 \mathrm{~d}$ and $\mathrm{S} 1 \uparrow$. The formation of typical fingerprint textures clearly indicates the presence of a $\mathrm{CN}$ structure during the formation of $\mathrm{CNC} / \mathrm{TiO}_{2}$ hybrid films. This feature is confirmed by performing time-lapse photography of a TAA/CNC suspension during EISA process, showing the formation of an iridescent film with time due to the local ordering of CNC in CN structure (Fig. S2 $\dagger$ ). Hence, our straightforward one-pot method enables to elaborate $\mathrm{CNC} / \mathrm{TiO}_{2}$ photonic hybrid films with tunable colors as well as a variable maximum of Bragg peak reflection (from the UV to the entire visible range). Although the CNC films are flexible with limited cracks, the photonic hybrid films are likely to crack in fragments whose size is getting smaller as the concentration of the TAA precursor increases. This is related to the water evaporation during EISA, which induces a shrinkage through the polycondensation of the titania precursor, generating capillary stress gradients within the films. The iridescent color rising from the films under natural light indicates the formation of the periodic structure reflecting a selective wavelength range. The color of the films turns from blue, green to yellow (Fig. 2a), in agreement with the redshifted maximum wavelength of the Bragg reflection (Fig. 2b). 
Increasing the TAA/CNC weight ratio induces a red-shift of the Bragg peak reflection as evidenced by UV-vis-NIR spectroscopy (Fig. 2b). The maximum wavelength reflected by the hybrid photonic films $\left(\lambda_{\max }\right)$ is related to the effective refractive index " $n_{\text {eff }}$ ", the pitch " $P$ " and the angle of the film axis to the emitted light following the equation: ${ }^{27}$

$\lambda_{\max }=n_{e f f} \cdot P \cdot \sin (\theta)$

Since the refractive index of the pure titania xerogel and CNC remain unchanged $\left(n_{\mathrm{TiO}_{2}}=1.9{ }^{28}\right.$ and $\left.n_{\mathrm{CNC}}=1.51^{29}\right)$, the redshift would probably rise from the increase of the pitch " $P$ ". To shed the light on our assumption, the cross-section of the films are analysed by SEM.
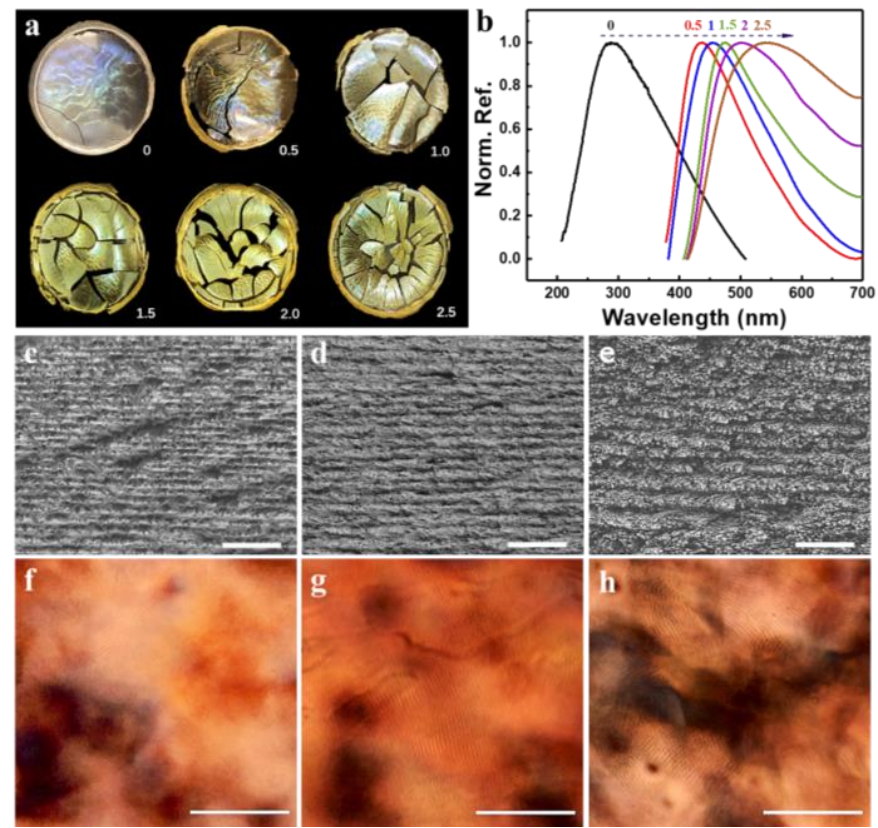

Fig. 2 (a) Photographs and (b) UV-Vis spectra of $\mathrm{CNC} / \mathrm{TiO}_{2}$ hybrid films. SEM images of $\mathrm{CNC} / \mathrm{TiO}_{2}$ hybrid films: (c) weight ratio=0.5, (d) weight ratio=1.5, (e) weight ratio=2.5 (scale bar $=1 \mu \mathrm{m}$ ). $\mathrm{POM}$ images of $\mathrm{CNC} / \mathrm{TiO}_{2}$ hybrid films: (f) weight ratio $=0.5$, (g) weight ratio $=1.5$, $(\mathrm{h})$ weight ratio $=2.5$ (scale bar $=50 \mu \mathrm{m})$.

The resulting $\mathrm{CN}$ structures in the $\mathrm{CNC} / \mathrm{TiO}_{2}$ hybrid films are further evidenced by the SEM imaging of the film crosssections (Fig. 2c-e, Fig. S3a and $\mathrm{b} \dagger$ ). A twisted structure, periodically repeated along the film axis, is observed whatever the composition of the film. This is a typical feature of the chiral nematic organization, which the distance between two layers correspond to the half-helical pitch " $P / 2$ " of the $\mathrm{CN}$ structure. ${ }^{30}$ Values of half-helical pitch estimated from these SEM images are found to increase with the titanium loading, confirming the effect of the TAA/CNC ratio on the observed $\lambda_{\max }$ red-shift (Table S1 $\uparrow$ ). Indeed, as suggested above, increasing of the $P$ value, likely due to the increasing of titania wall thickness (increase of the TAA concentration), induces a red-shift of the maximum Bragg peak reflection, in agreement with the UVvisible spectroscopic analysis (Fig. 2b). The photonic films have been further characterized using POM (Fig. 2f-h, Fig. S3c and $\mathrm{d} \dagger$ ). All the films show a strong birefringence but a random distribution of the dark and bright regions, suggesting a different orientation of the helical axis towards the up-coming light (random orientation of the liquid crystal domains). It should be noted the typical fingerprint textures are observed in POM images, which definitively confirm the preservation of the chiral nematic ordering in such as-prepared hybrid photonic films regardless of the titanium loading.

The inorganic $\mathrm{TiO}_{2}$ films are obtained after removal of the CNC template by annealing the samples at $500{ }^{\circ} \mathrm{C}$ under air following the procedure, described in Fig. 3a. Calcination can effectively remove the CNC from the hybrid films, as evidenced by FTIR spectroscopy (only the band corresponding to Ti-O bond is observed, Fig. $\mathrm{S} 4 \uparrow$ ) producing mesoporous $\mathrm{TiO}_{2}$ films as well as ensuring the cristallisation of $\mathrm{TiO}_{2}$ into its photoactive anatase phase. Nitrogen physisorption measurements confirm the mesoporous structure of the calcined films. Isotherms are reversible and the type IV characteristic hysteresis loop (obvious for higher TAA concentration) suggests interconnected pores with a cylindrical shape (Fig. S5a†). A well-defined progressive uptake measure at low relative pressure $\left(p / p_{0}=0.05-0.40\right)$ is characteristic of micropores, followed by a sudden increase due to the filling of the pore in the mesoporous range. The BET specific surface area reaches $64.5-72.6 \mathrm{~m}^{2} \mathrm{~g}^{-1}$ and the pore volume ranges from 0.35 to $0.14 \mathrm{~cm}^{3} \mathrm{~g}^{-1}$. The narrower pore size distribution implies identical pore for all the films, with an average pore diameter of $10 \mathrm{~nm}$, a value in agreement with the CNCs' width (Table S2 and Fig. S5b †). ${ }^{14}$ Wide-angle X-ray scattering (WAXS) patterns performed on hybrid photonic films before calcination display several peaks at $Q \sim 1.1 \AA^{-1}[(1 \overline{1} 0),(110)]$ and $1.6 \AA^{-1}(200)$, characteristics of cristalline form of CNC (Fig. 3b). ${ }^{31}$ After calcination, these peaks are no longer present in the calcined films but instead, we can observe the occurrence of broad diffraction peaks corresponding to nanosized $\mathrm{TiO}_{2}$ crystallites with anatase form (Fig. 3c). The calcined films observe by POM present in Fig. 3d show remarkable birefringent textures implying a preserved anisotropic structure (Fig. S6\%). In agreement with this statement, SEM images of the cross-sections of $\mathrm{TiO}_{2}$ films reveal a transfer of the alignment layers to mesostructured lamellar $\mathrm{TiO}_{2}$ (referenced as $\mathrm{L}-\mathrm{TiO}_{2}$ hereafter) with long-range order (Fig. 
$\mathbf{a}$

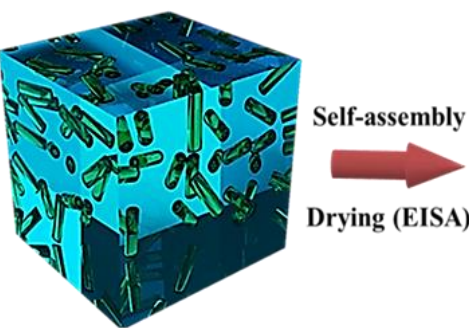

Aqueous ethanolic solution
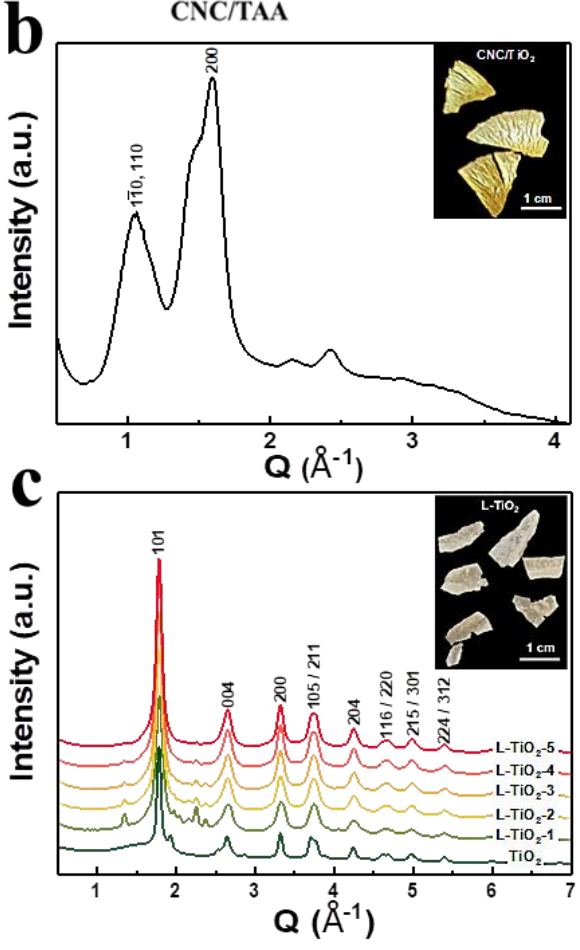

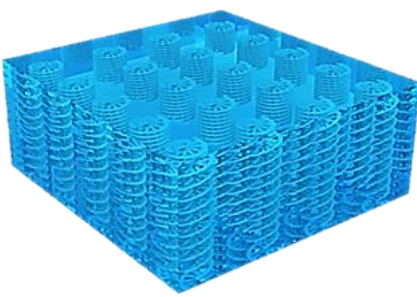

$\mathrm{CNC} / \mathrm{TiO}_{2}$ Hybrid photonic film
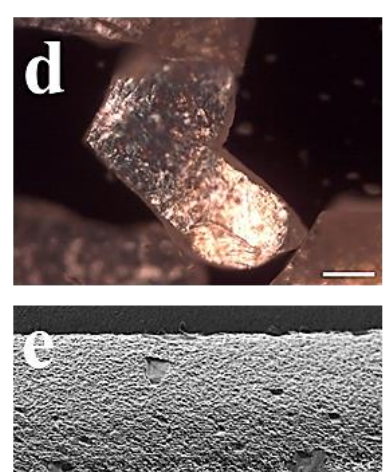

Annealling

(Shrinkage)

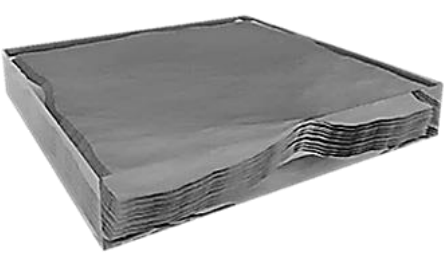

Lamellar $\mathrm{TiO}_{2}$ structure

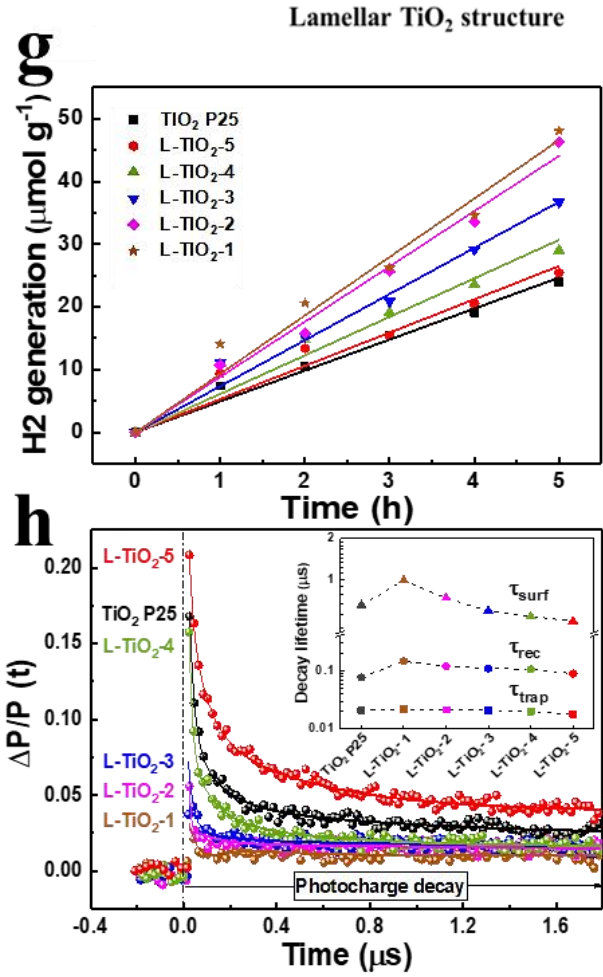

Fig. 3 (a) Schematic illustration of the fabrication of lamellar $\mathrm{TiO}_{2}$ structure $\left(\mathrm{L}-\mathrm{TiO}_{2}\right)$ after removal of the biotemplate by calcination. WAXS pattern of (b) CNC/TiO 2 hybrid film and (c) L-TiO ${ }_{2}$ films. (d) POM image of $\mathrm{L}_{-} \mathrm{TiO}_{2}-5$ film showing strong birefringence (scale bar $=100 \mu \mathrm{m}$ ). SEM images of (e) L-TiO ${ }_{2}-2$ and (f) L-TiO $2-5$ films (scale bar $=1$ $\mu \mathrm{m})$. (g) Hydrogen generation and (h) TRMC signals of $\mathrm{L}^{-} \mathrm{TiO}_{2}$ films and $\mathrm{TiO}_{2}-\mathrm{P} 25$ powder.

3e and $\mathrm{f}$ ). The layers parallel to the substrate are aligned predominantly with highly anisotropic structural features and the thickness of the layer increase as the TAA loading. The replica of the CN structure could not be confirmed from the SEM images, probably due to the crystal growth and sintering of the $\mathrm{TiO}_{2}$, or the movement of atoms occurring during the calcination step lead to the change of the chiral nematic structure to $1 \mathrm{D}$ lamellar one. These results evidence the change of the $\mathrm{CN}$ structure in $\mathrm{CNC} / \mathrm{TiO}_{2}$ hybrid films to inorganic $\mathrm{TiO}_{2}$ films with lamellar mesostructure.

The photocatalytic activity of the periodic long-range L$\mathrm{TiO}_{2}$ films is evaluated through hydrogen generation. The $\mathrm{L}-\mathrm{TiO}_{2}$ films show higher photoefficiency compared to standard $\mathrm{TiO}_{2}-$ P25 whatever the TAA/CNC ratio of the films (Fig. 3g). The $\mathrm{H}_{2}$ generation rate of $\mathrm{L}_{-} \mathrm{TiO}_{2}-1$ is $287.2 \mu \mathrm{mol} \mathrm{h}^{-1} \mathrm{~g}^{-1}$, as nearly twice as high as $\mathrm{TiO}_{2}-\mathrm{P} 25\left(153.1 \mu \mathrm{mol} \mathrm{h}{ }^{-1} \mathrm{~g}^{-1}\right)$. This result indicates that structuring the $\mathrm{TiO}_{2}$ material in a periodic long-range lamellar structure can considerably improve its photoefficiency for hydrogen generation. Interestingly, the TAA/CNC ratio of the starting material is inversely related to the photocatalytic efficiency of hydrogen generation. Consideration should be given to the interaction of light with these structured photocatalysts to understand deeply the relationship underlying between these results. Indeed, the light reflection in periodically structured material is reported to be an efficient strategy to improve the photon-to-charge carriers production. ${ }^{18}$ For instance, the photon velocity is slowing down significantly at the photonic band gap edges (blue and red) in photonic structure, increasing the absorbance light factor of $\mathrm{TiO}_{2} .{ }^{32}$ Bioinspired porous $\mathrm{TiO}_{2}$ material with a replica of chloroplast structure obtained from plant leaves shows enhanced light harvesting capability. ${ }^{7,33}$

The electronic properties of variable $\mathrm{L}-\mathrm{TiO}_{2}$ films are assessed by using time-resolved microwave conductivity (TRMC). The TRMC is a non-destructive and a contactless technique that enables to track the dynamics, the density and the lifetime of the photogenerated charge carriers on such periodic long-range lamellar mesostructured $\mathrm{TiO}_{2}$ films. ${ }^{34,35}$ 
After illumination, the TRMC signals rise following ultrafast charge separation process $(<200 \mathrm{fs}),{ }^{36}$ which is mainly due to mobile electrons at the surface of $\mathrm{TiO}_{2}$, since it is usually assumed that holes with a limited mobility remain on the bulk. The time-dependent change of microwave power transmission $\Delta P(t) / P$ is proportional to the photoconductivity $\Delta \sigma(\mathrm{t})$ variation and therefore proportional to the density of mobile charge carriers, which can be expressed as: ${ }^{37,38}$

$\frac{\Delta P}{P}(t)=\mathrm{A} \cdot \Delta \sigma(\mathrm{t})=A \cdot \sum \Delta n_{i}(t) \mu_{i}$

where $\Delta n_{i}(t)$ defines the density of photogenerated charge carriers " $i$ " at known time " $t$ ", and $\mu_{i}$ defines their mobility. In the present study, all TRMC measurements are recorded under $360 \mathrm{~nm}$ UV illumination, and with a light energy density received by the samples set at $1.4 \mathrm{~mJ} \mathrm{~cm}^{-2}$. According to the TRMC results, the photogenerated charge carriers associated with the TRMC signal gradually increase as the TAA/CNC ratio increases (Fig. 3h). Assuming an equal number of absorbed photons for all samples, we surmise that the improvement in the density of the photogenerated charge carriers may be related to the light scattering in the long-range lamellar $\mathrm{TiO}_{2}$ structure. As depicted in Fig. $3 e$ and $f$, the lamellar structure could be defined as alternating $\mathrm{TiO}_{2}$ layers separated by voids, having a variable refractive index. The thickness of the $\mathrm{TiO}_{2}$ layers increases with the ratio of TAA/CNC, which improves the confinement time of photons as well as their reflection. Therefore, the light propagation in such lamellar mesostructure improves the light harvesting and consequently the population of photogenerated charge carriers. TRMC results show an increase in the signal amplitude (which is correlated to the density of charge carriers $\mathrm{e}^{-} / \mathrm{h}^{+}$) with the TAA/CNC ratio (Fig. 3h), corresponding to an inverse correlation of $\mathrm{H}_{2}$ production efficiency. For example, $\mathrm{L}_{-} \mathrm{TiO}_{2}-1$ displays twice the hydrogen production efficiency of $\mathrm{L}^{-\mathrm{TiO}_{2}-5}$, while the population of photogenerated charge carriers are ten times less than $\mathrm{L}^{-\mathrm{TiO}_{2}-}$ 5. This result suggests that the density of charge carriers is probably not the limiting parameter for the $\mathrm{H}_{2}$ generation.

Thus, we turn to investigate the TRMC signals' decay, which typically occurs after the $\mathrm{e}^{-} / \mathrm{h}^{+}$production during the $8 \mathrm{~ns}$ laser pulse, giving useful information about the photocharge lifetime (Fig. 3h). The decay of the TRMC signals of photocharges can be divided into three decay stages: charge trapping $\left(\tau_{\text {trap }}\right)$, charge recombination $\left(\tau_{\text {rec }}\right)$ and surface reactions $\left(\tau_{\text {surf }}\right)$. The capture time of electrons and holes occurs in less than $30 \mathrm{ps}$, and it is accompanied by rapid recombination. ${ }^{39,40}$ Both of the trapping and recombination phenomena are considered as the main processes that can explain the TRMC signals' decay. ${ }^{41,42}$ The time constant of electrons trapping and recombination can be quantitatively estimated from the signal decay using the following equation: ${ }^{37}$

$$
\frac{\Delta P}{P}(t)=\sum A_{n} \cdot \exp \left(\frac{-t}{\tau_{n}}\right)
$$

where $A_{n}$ and $\tau_{n}$ are proportionality and time constants of each of the three decay processes, respectively. The photocharge lifetime presents in the inset of Fig. $3 \mathrm{~h}$ is found to be correlated with the wall thickness in the lamellar structure. The low charge carrier number produced at the surface of the $\mathrm{L}_{-} \mathrm{TiO}_{2}-1$ sample has the longest lifetime, which could be translated by low trapping and recombination yield. This trend evidences that $\mathrm{L}$ $\mathrm{TiO}_{2}-1$ synthesized at a lower TAA/CNC ratio shows weak electron trapping capability, thereby enhancing the proportion of active charges for $\mathrm{H}_{2}$ generation. The interfacial charge recombination is likely to occur in the boundaries (interfaces) of the long-range layers with thicker walls where defects could be localized.
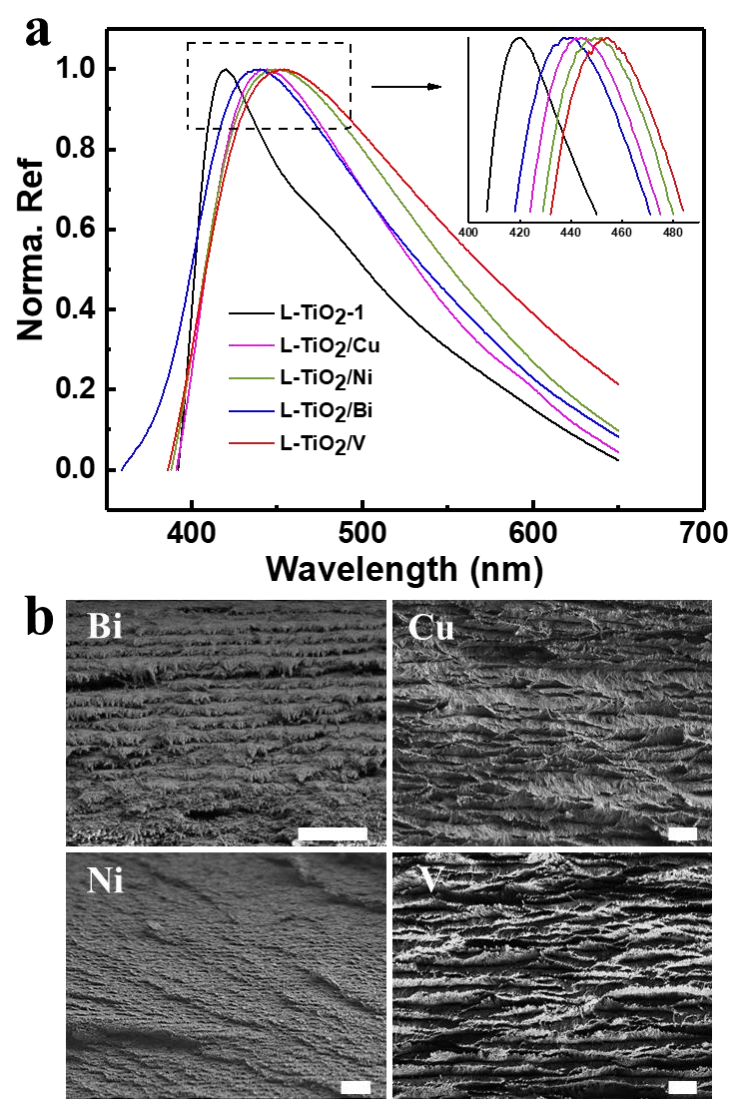

Fig. 4 (a) UV-Vis spectra and (b) SEM images of CNC/coupled metal oxide hybrid films (scale bar $=1 \mu \mathrm{m}$ ).

Owing to the interesting photoactivity of $\mathrm{L}_{-} \mathrm{TiO}_{2}-1$ for hydrogen generation, several coupling schemes $(\mathrm{Cu}, \mathrm{Ni}, \mathrm{Bi}, \mathrm{V})$ have been performed to improve the photoefficiency yield even further. Metal oxide coupled to $\mathrm{TiO}_{2}$ can trap electrons, which impedes the recombination of $\mathrm{e}^{-} / \mathrm{h}^{+}$resulting in a significantly enhance of photocatalytic activity. ${ }^{43,44}$ The solubility of the metals precursors combine to the one-pot self-assembly method enables to elaborate biotemplated coupled metal oxides. The photonic colors rising from the light reflection at the surface of hybrid films ( $\mathrm{CNC} /$ coupled metal oxides) do not show a notable variation (Fig. S7 $\dagger$ ), which is consistent with the slight red-shift in Bragg peak reflection (Fig. 4a). SEM images evidence the remaining of the twisted periodic structure, as already observed for the $\mathrm{CNC} / \mathrm{TiO}_{2}$ hybrid films (Fig. 4b). This shows for the first time that the proposed one-pot self-assembly method could be extended to the elaboration of coupled metal oxides with mesostructured architecture. 

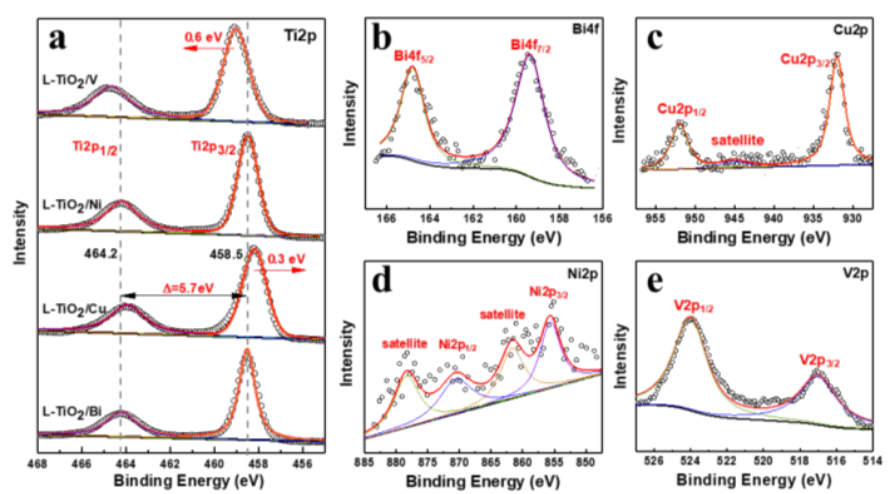

Fig. 5 (a) XPS spectra of Ti2p of different coupled metal oxides. XPS spectra of (b) L-TiO $/$ Bi, (c) $\mathrm{L}^{-\mathrm{TiO}_{2}} / \mathrm{Cu}$, (d) $\mathrm{L}-\mathrm{TiO}_{2} / \mathrm{Ni}$ and (e) $\mathrm{L}-\mathrm{TiO}_{2} / \mathrm{V}$.

The compositions of the mixed oxides with lamellar structure are confirmed by X-ray photoelectron spectroscopy (XPS). The general XPS spectra of the films show detection of carbon and oxygen elements (Fig. S8 $\dagger$ ). The films show Ti2p peak deconvoluted into two curves, which can be assigned to the spin-orbit components $2 p_{3 / 2}$ and $2 p_{1 / 2}$, respectively. The separations between the $\mathrm{Ti} 2 \mathrm{p}_{3 / 2}$ and $\mathrm{Ti} 2 \mathrm{p}_{1 / 2}$ peaks are measured to be $5.7 \mathrm{eV}$ for all the films, in agreement with the binding energy (BE) separation observed for anatase $\mathrm{TiO}_{2}$ (Fig. 5a). ${ }^{45,46}$ XPS spectra of the target metal oxides are presented in Fig. 5 be. In the case of bismuth oxide coupled with $\mathrm{L}^{-\mathrm{TiO}_{2}-1}$, symmetric peaks of $\mathrm{Bi} 4 \mathrm{f}$ state are observed. The $\mathrm{Bi} 4 \mathrm{f}_{7 / 2}$ and $\mathrm{Bi} 4 \mathrm{f}_{5 / 2}$ asymmetric bands are both resolved into two bands, at $159 \mathrm{eV}$ and $165 \mathrm{eV}$, respectively (Fig. 5 b). ${ }^{47}$ These orbits correspond to $\mathrm{Bi}^{3+}$ oxide state in $\mathrm{Bi}_{2} \mathrm{O}_{3}$, and the slight shift to lower binding energy could be due to oxygen vacancies. ${ }^{48}$ The XPS spectra of $\mathrm{L}-\mathrm{TiO}_{2} / \mathrm{Cu}$ shows characteristic peaks of $\mathrm{Cu} 2 \mathrm{p}_{3 / 2}$ and $\mathrm{Cu} 2 \mathrm{p}_{1 / 2}$ levels are respective at the $\mathrm{BE} 932.5 \mathrm{eV}$ and $952.1 \mathrm{eV}$, corresponding to $\mathrm{Cu}(\mathrm{I})$ species in cuprous oxide. ${ }^{49,50}$ The weak satellite observed at $945 \mathrm{eV}$ also demonstrated the presence of $\mathrm{Cu}(\mathrm{I})$ (Fig. $5 \mathrm{c}$ ). In the case of $\mathrm{Ni}$ oxides $\left(\mathrm{L}-\mathrm{TiO}_{2} / \mathrm{Ni}\right)$, two peaks at $\mathrm{BE}$ of $873.7 \mathrm{eV}$ and $855.1 \mathrm{eV}$ correspond to $\mathrm{Ni} 2 \mathrm{p}_{1 / 2}$ and $\mathrm{Ni} 2 \mathrm{p}_{3 / 2}$, respectively, and their corresponding satellites at $880 \mathrm{eV}$ and $861 \mathrm{eV}$ (Fig.5 d). These peaks are assigned to $\mathrm{Ni}^{2+}$ in $\mathrm{Ni}(\mathrm{OH})_{2}$ (derived from the oxidation of $\mathrm{NiO}$ ). ${ }^{52}$ As seen in Fig. 5e, the $\mathrm{BE}$ of $\mathrm{V} 2 \mathrm{p}_{3 / 2}, \mathrm{~V} 2 \mathrm{p}_{1 / 2}$ and $\mathrm{O} 1 \mathrm{~s}$ are locked at $517.4,524.8$ and $530 \mathrm{eV}$, respectively, agree well with $\mathrm{V}^{5+}$ and $\mathrm{O}^{2-}$ in $\mathrm{V}_{2} \mathrm{O}_{5} .{ }^{52,53}$ The films are observed using transmission electron microscopy (TEM) and the results are shown in Fig. S9†. TEM micrograph show a porous structure in agreement with the BET analysis. However, the lamellar structure of the films is not observed mainly because of the layers are parallel to the substrate. The UV-vis absorption spectra of $\mathrm{L}-\mathrm{TiO}_{2}$ and different metal oxides coupled to $\mathrm{TiO}_{2}$ are shown in Fig. $\mathrm{S} 10 \uparrow$. The $\mathrm{L}-\mathrm{TiO}_{2}$ is observed at about $400 \mathrm{~nm}$, characteristic of the absorption of the anatase form. After coupling $\mathrm{L}-\mathrm{TiO}_{2}$ with different metal oxides, a redshift is observed confirming the contribution of the mixed oxides. The maximum red-shift is observed for copper oxide and vanadium oxide compared to nickel and bismuth oxides.
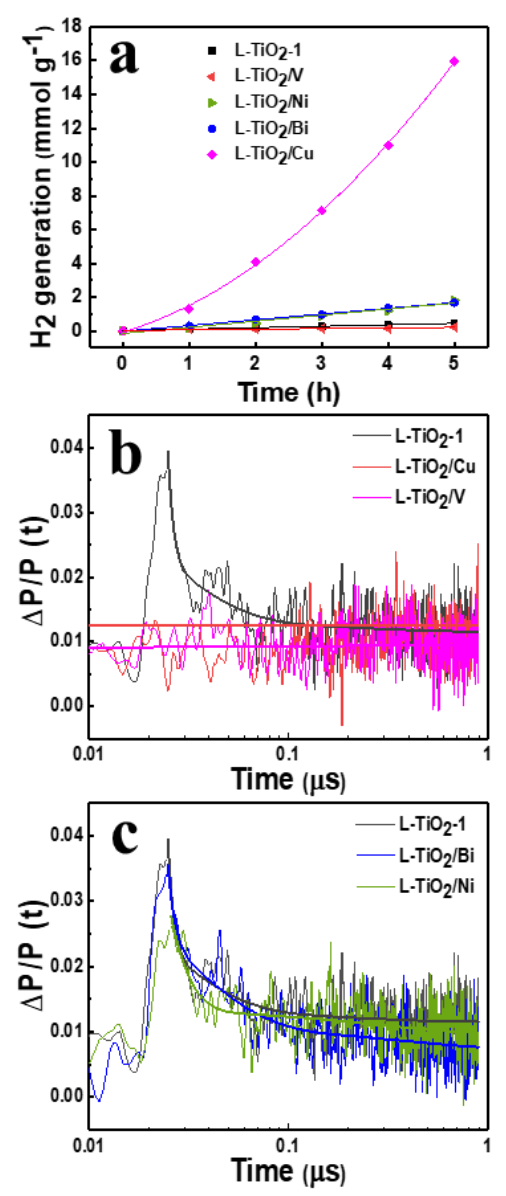

Fig. 6 (a) Hydrogen generation of mixed oxides films with lamellar structure. TRMC signals of (b) $\mathrm{L}-\mathrm{TiO}_{2} / \mathrm{Cu}$ and $\mathrm{L}-\mathrm{TiO}_{2} / \mathrm{V}$, (c) L-TiO $/ \mathrm{Li}_{2}$ and $\mathrm{L}-\mathrm{TiO}_{2} / \mathrm{Ni}$.

The photocatalytic performances of metal oxides coupled to $\mathrm{L}^{-\mathrm{TiO}_{2}-1}$ show variable photoefficiencies (Fig. 6a). For instance, $\mathrm{L}-\mathrm{TiO}_{2} / \mathrm{Cu}$ exhibits the highest $\mathrm{H}_{2}$ generation rate, 7.88 mmol h-1 $\mathrm{g}^{-1}$, which is 40 -times higher than solely $\mathrm{L}^{-\mathrm{TiO}_{2}-1}$. The $\mathrm{H}_{2}$ generation rates using $\mathrm{Ni}$ and $\mathrm{Bi}$ are, $1.0 \mathrm{mmol} \mathrm{h}^{-1} \mathrm{~g}^{-1}$ and 0.9 $\mathrm{mmol} \mathrm{h} \mathrm{h}^{-1} \mathrm{~g}^{-1}$, respectively, twice that obtained from $\mathrm{L}^{-\mathrm{TiO}_{2}-1}$. However, when $V$ is involved, the photocatalytic activity deteriorates, implying an inactivation of the $\mathrm{L}_{-} \mathrm{TiO}_{2}$. According to the TRMC investigations of these photocatalysts, the $\mathrm{L}-\mathrm{TiO}_{2}-$ 1 mixed with either Cu or $V$ shows no signal (Fig. 6b). In the first case, $\mathrm{Cu}$ acts as an electrons collector for better charge carriers separation and accelerates the reaction rate of hydrogen reduction, while $\mathrm{V}^{5+}$ state is considered as a recombination center that inhibits the $\mathrm{H}_{2}$ production. ${ }^{54,55}$ The position of the $\mathrm{Cu}_{2} \mathrm{O}$ conduction band makes the thermodynamical transfer of electrons, resulting in the special charge carriers separation. ${ }^{56-}$ 58 The recombination of $\mathrm{e}^{-} / \mathrm{h}^{+}$in $\mathrm{TiO}_{2}$ is prevented by efficient inter-particle charge transfer leading to improve the hydrogen generation photoefficiency of $\mathrm{L}-\mathrm{TiO}_{2} / \mathrm{Cu} .{ }^{59,60}$ Furthermore, the $\mathrm{BE}$ of $\mathrm{Ti} 2 \mathrm{p}$ shifts to lower energy $(0.3 \mathrm{eV})$ in $\mathrm{L}^{-\mathrm{TiO}_{2}} / \mathrm{Cu}$, suggesting partial surface reduction through the formation of oxygen vacancies and lower $\mathrm{Ti}$ oxidation state $\left(\mathrm{Ti}^{3+}\right)$, which was reported to boost the photocatalytic activity of $\mathrm{TiO}_{2} \cdot 61,62$ Conversely, $\mathrm{L}-\mathrm{TiO}_{2} / \mathrm{V}$ exhibits a slightly higher $\mathrm{BE}$ of Ti2p $(0.6 \mathrm{eV})$ forming a higher average oxidation state of $\mathrm{Ti}$ ions (Fig. 5a). ${ }^{63}$ $\mathrm{NiO}$, as well as $\mathrm{Bi}_{2} \mathrm{O}_{3}\left(2.8 \mathrm{eV}^{64}\right)$, can form a p-n junction with $\mathrm{TiO}_{2}$, 
generating an internal electric field, thereby giving similar inhibition to the $\mathrm{e} / \mathrm{h}^{+}$recombination. ${ }^{65} \mathrm{~A}$ similar conclusion can be drawn from the TRMC signal (Fig. 6c), where the increase of the decay rate evidence efficient electrons capture.

\section{Conclusions}

In summary, we report the first demonstration of a simple and reliable one-pot sol-gel self-assembly method for the design of a layered photocatalyst in controlled architecture. The coassembly of water-soluble titanium diisopropoxide bis(acetylacetonate) precursor and the lyotropic cellulose nanocrystal dispersion allows the formation of $\mathrm{CNC} /$ titania hybrid material containing chiral nematic structure. Successfully removal of biotemplate generates a lamellar mesostructure whose birefringence is rising from its anisotropic structure. This kind of long-range ordered lamellar structure can improve the capability of light harvesting and extension of the charge carriers lifetime. The straightforward self-assembly method can be easy speared to the coupling of $\mathrm{TiO}_{2}$ with different metal oxides to further enhance its photoefficiency, resulting in higher hydrogen generation. This work offers an easy way to design lamellar mesostructured photocatalyst with the ability to extend charge carriers lifetime, which opens new avenue for photocatalytic and solar energy conversion.

\section{Conflicts of interest}

There are no conflicts to declare.

\section{Acknowledgements}

Cong Wang acknowledges the China Scholarship Council (CSC) for his fellow research position. The authors thank Marie-Claire Schanne-Klein for full access to the polarized optical microscope and François Brisset for collecting the SEM and TEM images. Jian $\mathrm{Li}$ acknowledges the public grant overseen by the French National Research Agency (ANR) as part of the "Investissements d'Avenir" program (Labex NanoSaclay, reference: ANR-10LABX-0035) for his post-doc position.

\section{Notes and references}

1 J. B. Sambur, T. Y. Chen, E. Choudhary, G. Chen, E. J. Nissen, E. M. Thomas, N. Zou and P. Chen, Nature., 2016, 530, 77-80.

2 S. Nishimura, N. Abrams, B. A. Lewis, L. I. Halaoui,T. E. Mallouk, K. D. Benkstein, J. Lagemaat and A. J. Frank, J. Am. Chem. Soc. 2003, 125, 6306-6310.

3 S. Guldin, S. Huttner, M. Kolle, M. E. Welland, P. M. Buschbaum, R. H. Friend, U. Steiner and N. Tetreault, Nano. Lett., 2010, 10, 2303-2309.

4 J. T. Park, J. H. Prosser, S. H. Ahn, S. J. Kim, J. H. Kim, D. Lee, Adv. Funct. Mater., 2013, 23, 2193-2200.

5 C. T. Dinh, H. Yen, F. Kleitz and T. O. Do, Angew. Chem. Int. Ed. Engl., 2014, 53, 6618-6623.

6 H. Zhao, Z. Hu, J. Liu, Y. Li, M. Wu, G. Van Tendeloo and B.-L. Su, Nano Energy, 2018, 47, 266-274.

$7 \quad$ X. Li, T. Fan, H. Zhou, S.-K. Chow, W. Zhang, D. Zhang, Q. Guo and H. Ogawa, Adv. Funct. Mater., 2009, 19, 45-56.
$8 \quad$ M. Giese, L. K. Blusch, M. K. Khan and M. J. MacLachlan, Angew. Chem. Int. Ed., 2015, 54, 2888-2910.

9 H. Kargarzadeh, J. Huang, N. Lin, I. Ahmad, M. Mariano, A. Dufresne, S. Thomas and A. Gałęski, Prog. Polym. Sci., 2018, 87, 197-227.

10 K. E. Shopsowitz, H. Qi, W. Y. Hamad and M. J. Maclachlan, Nature, 2010, 468, 422-425.

11 K. E. Shopsowitz, W. Y. Hamad and M. J. MacLachlan, J. Am. Chem. Soc., 2012, 134, 867-870.

12 M. K. Khan, M. Giese, M. Yu, J. A. Kelly, W. Y. Hamad and M. J. MacLachlan, Angew. Chem. Int. Ed., 2013, 52, 8921-8924.

13 K. E. Shopsowitz, J. A. Kelly, W. Y. Hamad and M. J. MacLachlan, Adv. Funct. Mater., 2014, 24, 327-338.

14 A. Ivanova, D. Fattakhova-Rohlfing, B. E. Kayaalp, J. Rathousky and T. Bein, J. Am. Chem. Soc., 2014, 136, 5930-5937.

15 A. Ivanova, M. C. Fravventura, D. Fattakhova-Rohlfing, J. Rathouský, L. Movsesyan, P. Ganter, T. J. Savenije and T. Bein, Chem. Mater., 2015, 27, 6205-6212.

16 J. Xue, F. Song, X.-W. Yin, Z.-L. Zhang, Y. Liu, X.-L. Wang and Y.Z. Wang, ACS. Sustain. Chem. Eng., 2017, 5, 3721-3725.

17 J. A. Kelly, M. Giese, K. E. Shopsowitz, W. Y. Hamad and M. J. MacLachlan, Acc. Chem. Res., 2014, 47, 1088-1096.

18 G. D. Gesesse, C. Li, E. Paineau, Y. Habibi, H. Remita, C. ColbeauJustin and M. N. Ghazzal, Chem. Mater., 2019, 31, 4851-4863.

19 T. D. Nguyen, J. Li, E. Lizundia, M. Niederberger, W. Y. Hamad and M. J. MacLachlan, Adv. Funct. Mater., 2019, 29, 19046391904648.

20 K. E. Shopsowitz, A. Stahl, W. Y. Hamad and M. J. MacLachlan, Angew. Chem. Int. Ed., 2012, 51, 6886-6890.

21 T. D. Nguyen, E. Lizundia, M. Niederberger, W. Y. Hamad and M. J. MacLachlan, Chem. Mater., 2019, 31, 2174-2181.

22 M. N. Ghazzal, D. P. Debecker and E. M. Gaigneaux, Thin Solid Films, 2016, 611, 117-124.

23 M. N. Ghazzal, E. Aubry, N. Chaoui and D. Robert, Beilstein. J. Nanotech., 2015, 6, 2039-2045.

24 L. Zhong, S. Fu, X. Peng, H. Zhan and R. Sun, Carbohyd. Polym., 2012, 90, 644-649.

25 C. Li, J. Evans, N. Wang, T. Guo and S. He, Sci. Rep., 2019, 9, 11290.

26 P. X. Wang, W. Y. Hamad and M. J. MacLachlan, Nat. Commun., 2016, 7, 11515.

27 H. D. Vries, Acta Crystallogr, 1951, 4, 219-226.

28 S. Lisinski, J. Krause, D. Schaniel, L. Ratke and T. Woike, Scripta. Mater., 2008, 58, 553-555.

29 J. D. Kittle, X. Du, F. Jiang, C. Qian, T. Heinze, M. Roman and A. R. Esker, Biomacromolecules, 2011, 12, 2881-2887.

30 J. Majoinen, E. Kontturi, O. Ikkala and D. G. Gray, Cellulose, 2012, 19, 1599-1605.

31 A. D. French, Cellulose, 2013, 21, 885-896.

32 N. Abrams. S. Nishimura, B. A. Lewis, L. I. Halaoui, K. D. Benkstein, T. E. Mallouk, J. Lagemaat and A. J. Frank, J. Am. Chem. Soc., 2003, 125, 6306-6310.

33 H. Zhou, X. Li, T. Fan, F. E. Osterloh, J. Ding, E. M. Sabio, D. Zhang and Q. Guo, Adv. Mater., 2010, 22, 951-956.

34 M. Kunst and K. M. Schindler, J. Phys. Chem., 1990, 94, 82228226.

35 T. J. Savenije, J. E. Kroeze and J. M. Warman, J. Am. Chem. Soc., 2004, 126, 7608-7618.

36 D. B. Liston, N. J. Cherepy, J. A. Lovejoy, H. Deng and J. Z. Zhang, Appl. Catal. B. Environ., 1998, 102, 770-776.

37 N. Delegan, R. Pandiyan, S. Johnston, A. Dirany, S. Komtchou, P. Drogui and M. A. El Khakani, J. Phys. Chem. C., 2018, 122 5411-5419.

38 R. Katoh, A. Furube, K.-i. Yamanaka and T. Morikawa, J. Phys. Chem. Lett., 2010, 1, 3261-3265.

39 N. Serpone and A. Salinaro, Pure \& Appl. Chem., 1999, 71, $303-$ 320.

40 S. Nakajima and R. Katoh, J. Mater. Chem. A., 2015, 3, 1546615472. 
41 T. J. Savenije, A. Huijser, M. J. W. Vermeulen and R. Katoh, Chem. Phys. Lett., 2008, 461, 93-96.

42 M. Kunst, F. Goubard, C. Colbeau-Justin and F. Wünsch, Mat. Sci\&Eng. C., 2007, 27, 1061-1064.

43 Z. Hai, N. E. Kolli, D. B. Uribe, P. Beaunier, M. Jose-Yacaman, J. Vigneron, A. Etcheberry, S. Sorgues, C. Colbeau-Justin, J. Chen and H. Remita, J. Mater. Chem. A., 2013, 1, 10829-10835.

44 G. D. Gesesse, T. Le Neel, Z. Cui, G. Bachelier, H. Remita, C. Colbeau-Justin and M. N. Ghazzal, Nanoscale, 2018, 10, 2014020146.

45 M. N. Ghazzal, O. Deparis, J. De Coninck and E. M. Gaigneaux J. Mater. Chem. C., 2013, 1, 6202-6209.

46 M. N. Ghazzal, H. Kebaili, M. Joseph, D. P. Debecker, P. Eloy, J. De Coninck and E. M. Gaigneaux, Appl. Catal. B. Environ., 2012, 115-116, 276-284.

47 W. Luo, F. Li, Q. Li, X. Wang, W. Yang, L. Zhou and L. Mai, ACS Appl. Mater. Inter., 2018, 10, 7201-7207.

48 Y. Liang, J. Manioudakis, J. R. Macairan, M. S. Askari, P. Forgione, R. Naccache, ACS Omega, 2019, 4, 14955-14961.

49 J. Fan, Y. H. Dai, Y. L. Li, N. F. Zheng, J. F. Guo, X. Q. Yan and G. D. Stucky, J. Am. Chem. Soc., 2009, 131, 15568-15569.

50 J. Li, L. Liu, Y. Yu, Y. Tang, H. Li and F. Du, Electrochem.Commun., 2004, 6, 940-943.

51 L. Chen, J. Zhang, X. Ren, R. Ge, W. Teng, X. Sun and X. Li, Nanoscale, 2017, 9, 16632-16637.

52 V. Bondarenka, S. Kačiulis, Z. Martūnas, A. Rèza, G.J. Babonas and A. Pašiškevičius, Lith. J. Phys., 2008, 48, 341-348.

53 G. Silversmit, D. Depla, H. Poelman, G. B. Marin and R. D. Gryse, Surf. Sci., 2006, 600, 3512-3517.

54 A. D. Paola, G. Marci, L. Palmisano, M. Schiavello, K. Uosaki, S. Ikeda and B. Ohtani, J. Phys. Chem. B., 2002, 106, 637-645.

55 S. Stoyanov, D. Mladenova and C. Dushkin, React. Kinet. Mech. Cat. 2006, 88, 277-283.

56 S. Chen and L. W. Wang, Chem. Mater., 2012, 24, 3659-3666.

57 M. E. Aguirre, R. Zhou, A. J. Eugene, M. I. Guzman and M. A. Grela, Appl. Catal. B. Environ., 2017, 217, 485-493.

58 A. Visible, R. B. Wang, A. Vertova, S. Rondin, A. Minguzzi, E. Ahlberg and M. Busch, Chem. Mater., 2019, 31, 4787-4792.

59 S. Xu and D. D. Sun, Int. J. Hydrogen. Enreg., 2009, 34, 60966104.

60 N. Lakshmana Reddy, S. Emin, M. Valant and M. V. Shankar, Int J. Hydrogen. Enreg., 2017, 42, 6627-6636.

61 S. Wang, L. Pan, J. J. Song, W. Mi, J. J. Zou, L. Wang and X. Zhang, J. Am. Chem. Soc., 2015, 137, 2975-2983.

62 R. Ren, Z. Wen, S. Cui, Y. Hou, X. Guo and J. Chen, Sci. Rep., 2015, 5, 10714.

63 W. Choi, A. Termin and M. R. Hoffmann, J. Phys. Chem., 1994, 98, 13669-13679.

64 Y. Peng, M. Yan, Q.-G. Chen, C.-M. Fan, H.-Y. Zhou and A.-W. $\mathrm{Xu}$, J. Mater. Chem. A, 2014, 2, 8517-8524.

65 S. A. Rawool, M. R. Pai, A. M. Banerjee, A. Arya, R. S. Ningthoujam, R. Tewari, R. Rao, B. Chalke, P. Ayyub, A. K. Tripathi and S. R. Bharadwaj, Appl. Catal. B. Environ., 2018, 221 443-458. 


\section{Electronic Supplementary Information (ESI)}

\section{Sol-Gel Biotemplating Route with Cellulose Nanocrystals to Design Photocatalyst Boosting the Hydrogen Generation}

Cong Wang, ${ }^{\mathrm{a}}$ Jian Li, ${ }^{\mathrm{a}}$ Erwan Paineau, ${ }^{\mathrm{b}}$ Abdelghani Laachachi, ${ }^{\mathrm{c}}$ Christophe Colbeau-Justin, ${ }^{\mathrm{a}}$ Hynd Remita $^{\text {a,d }}$ and Mohamed Nawfal Ghazzal*a

${ }^{a}$ Institut de Chimie Physique, UMR 8000 CNRS, Université Paris-Saclay 91405 Orsay, France.

${ }^{b}$ Laboratoire de Physique du Solide, UMR 8502 CNRS, Université Paris-Saclay 91405 Orsay, France.

${ }^{c}$ Materials Research and Technology Department (MRT), Luxembourg Institute of Science and Technology (LIST), 5 Rue Bommel - ZAE Robert Steichen, 4940 Käerjeng, Luxembourg.

${ }^{d}$ CNRS, Institut de Chimie Physique, UMR 8000, 91405 Orsay, France.

*Corresponding Author:

mohamed-nawfal.ghazzal@universite-paris-saclay.fr 
Table of Contents

1. Experiment Procedures $\quad$ S3

1.1 Materials $\quad$ S3

1.2 Material characterization $\quad$ S3

2. Figures S1-S10 S4

3. Tables S1-S2 S9

4. References $\quad$ S9 


\section{Experimental details}

\subsection{Materials}

All solvents and reagents including TAA (Titanium diisopropoxide bis(acetylacetonate), 75 wt.\% in isopropanol) and CNC (Cellulose Nanocrystals, obtained from University of MAINE) were used without further purification.

\subsection{Material characterization}

The textures of suspensions (pure $\mathrm{CNC}$ and $\mathrm{CNC} / \mathrm{TAA}$ ) and films ( $\mathrm{CNC} / \mathrm{TAA}$ hybrid films and lamellar $\mathrm{TiO}_{2}$ films) were recorded by polarizing optical microscopy (POM) between crossed polarizers on a Zeiss Axio-Observer equipped with a Sony Cyber-shot DSC-W570.

The UV-vis spectroscopy (model Cary 5000 series, Agilent Technologies) was used to analyze the optical properties of the hybrid films. The maximum reflectance was set to $100 \%$ using tetrafluoroethylene as a reference in a wavelength range between 200 and $800 \mathrm{~nm}$.

The cross-sections of the hybrid films and lamellar films were measured by scanning electron microscopy (SEM). The SEM image was acquired with a ZEISS Supra 55VP FEG-SEM with an operating voltage of $2 \mathrm{kV}$ and a working distance of 3 to $5.7 \mathrm{~mm}$.

The morphology of lamellar films was studied by transmission electron microscopy (TEM, JEOL JEM 2100Plus), operating at $200 \mathrm{kV}$. The films were dipersed in ethanol solution followed by sonication, before and then drop-casting on carbon-coated copper grids. The grids were dried under air prior to any use.

Wide-angle X-ray scattering (WAXS) measurements were performed on a molybdenum rotating anode generator $\left(\lambda_{\mathrm{MoK}_{\alpha}}=0.711 \AA\right.$, Rigaku Corp., Japan) equipped with a multilayer W/Si mirror (Osmic) providing a monochromatic beam of $1 \mathrm{x} 1 \mathrm{~mm}^{2}$ at the sample position. Two-dimensional WAXS patterns were collected on a MAR345 detector (marXperts $\mathrm{GmbH}$, Germany) with $150 \mu \mathrm{m}$ pixel size, placed at a sample-to-detector distance of $150 \mathrm{~mm}$. The typical accessible range of scattering vector modulus $Q$ was $0.4-7 \AA-1(Q=4 \pi / \lambda \sin (\theta)$, where $\lambda$ is the incident wavelength and $2 \theta$ is the scattering angle) ${ }^{[1]}$ Scattered intensity $I$ as a function of the scattering vector modulus $Q$ is obtained by angular integration over the $2 \mathrm{D}$ scattering patterns using homemade software. The hydrogen generation was performed in a closed quartz reactor ( $10 \mathrm{~mL}$ volume). $4 \mathrm{mg}$ mesoporous lamellar $\mathrm{TiO}_{2}$ or coupled metal oxide films was cracked into small pieces and suspended in $4 \mathrm{~mL}$ degassed aqueous methanol solution $\left(3 \mathrm{~mL} \mathrm{H}_{2} \mathrm{O}, 1 \mathrm{~mL}\right.$ methanol). The Oriel $300 \mathrm{~W}$ Xenon lamp with an infrared water filter was employed to irradiate the samples for 5 hours under stirring. 0.2 $\mathrm{mL}$ gas samples were taken from the quartz cell with a syringe every hour, and the amount of $\mathrm{H}_{2}$ was measured by gas chromatography (Shimadzu GC-14B).

The electronic properties of the lamellar $\mathrm{TiO}_{2}$ films and metals loaded $\mathrm{TiO}_{2}$ were characterized by the time-resolved microwave conductivity (TRMC) technique. The laser pulses (OPO lasers, EKSPLA, NT342B tunable in the 200-2000 $\mathrm{nm}$ range) were used as excitation sources for the parametric oscillator, providing $8 \mathrm{~ns}$ pulses and $10 \mathrm{~Hz}$ frequencies. ${ }^{\left[{ }^{[2]}\right.}$ The incident microwave is generated using a $30 \mathrm{GHz}$ Gunn diode.

The X-ray photoelectron spectroscopies (XPS) of different metals loaded $\mathrm{TiO}_{2}$ were obtained on an $\mathrm{ESCALAB} 250$ spectrophommeter with $\mathrm{Al}-\mathrm{K} \alpha$ radiation. The binding energies were calibrated using $\mathrm{C} 1 \mathrm{~s}$ at $284.6 \mathrm{eV}$.

Fourier-transform infrared (FTIR) spectra of $\mathrm{CNC}$ film and $\mathrm{CNC} / \mathrm{TiO}_{2}$ hybrid films were carried out on a FTIR spectrometer (Bruker Vertex 70) equipped with a diamond ATR apparatus (PIKEMIRACLE crystal plate diamond/ZnSe) and an MCT detector. All samples were placed on clean $\mathrm{ZnSe}$ diamond plate and 100 scans were performed at a spectral resolution of $4 \mathrm{~cm}^{-1}$ in the range of $600-4000 \mathrm{~cm}^{-1}$.

Nitrogen physisorption was performed at $-196.15{ }^{\circ} \mathrm{C}$ on a Micromeritics instrument. The samples were outgassed overnight at $120^{\circ} \mathrm{C}$ in vacuum $(7 \mathrm{~Pa})$ to remove water and subsuquent remaining carbone into the pore. The specific surface area was obtained from the Brunauer, Emmett et Teller (BET) method between 0.05 and $0.50 \mathrm{P} / \mathrm{P}_{0}$. The pore size distribution were deduced from the adsorption branch using the BJH method. 


\section{Figures S1-S10}

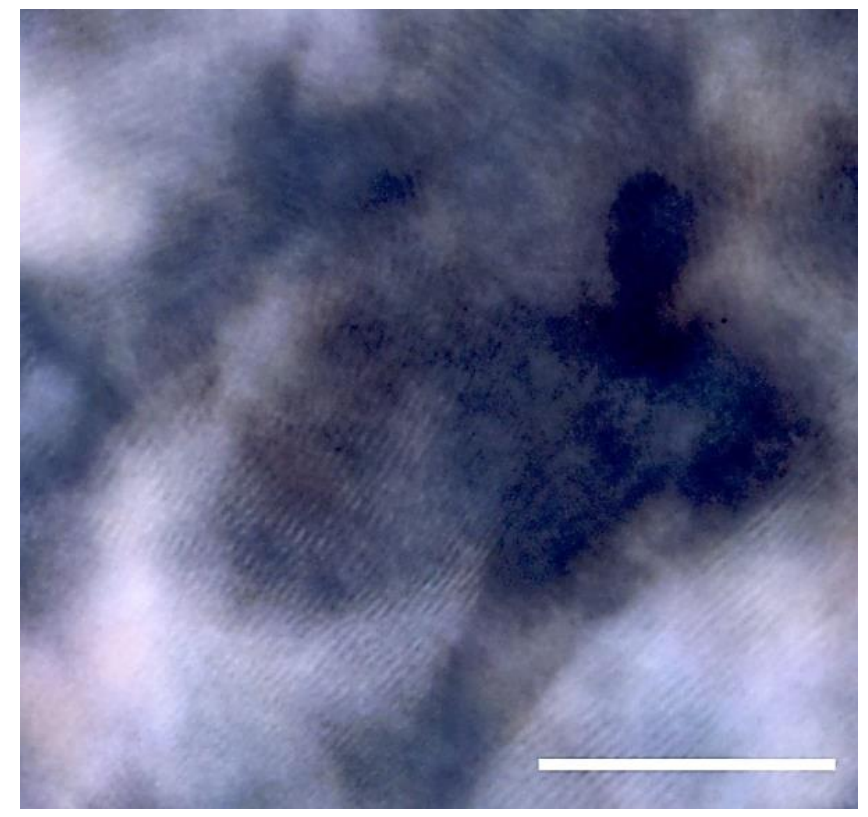

Fig. S1 POM image obtained between crossed polarizers of a TAA/CNC (weith ratio=1) solution during slow evaporation at room temperature (scale bar $=50 \mu \mathrm{m})$.

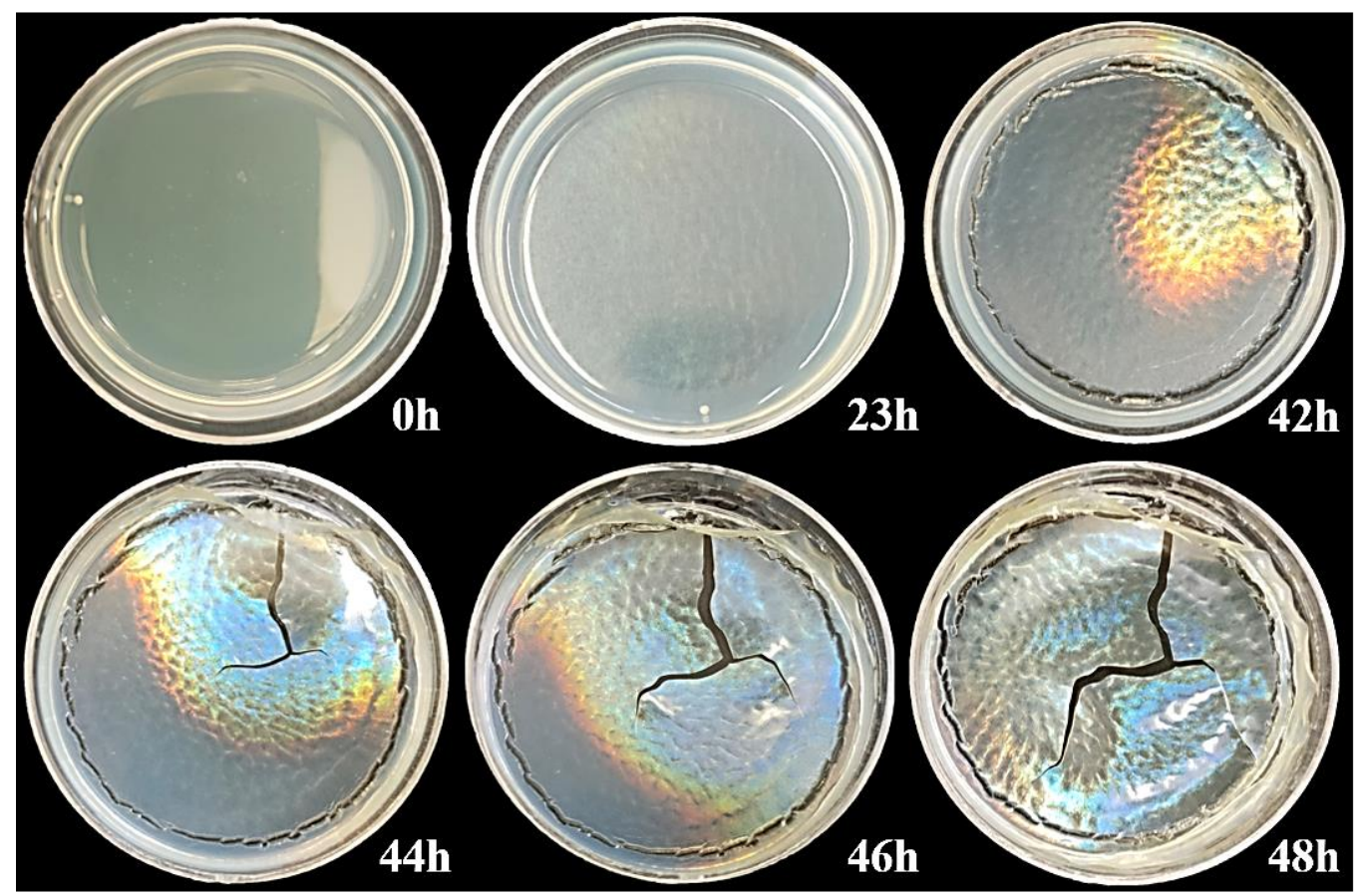

Fig. S2 Time-lapse photography of the EISA process for $\mathrm{CNC} / \mathrm{TiO}_{2}$ (weight ratio=0.5) hybrid film. 

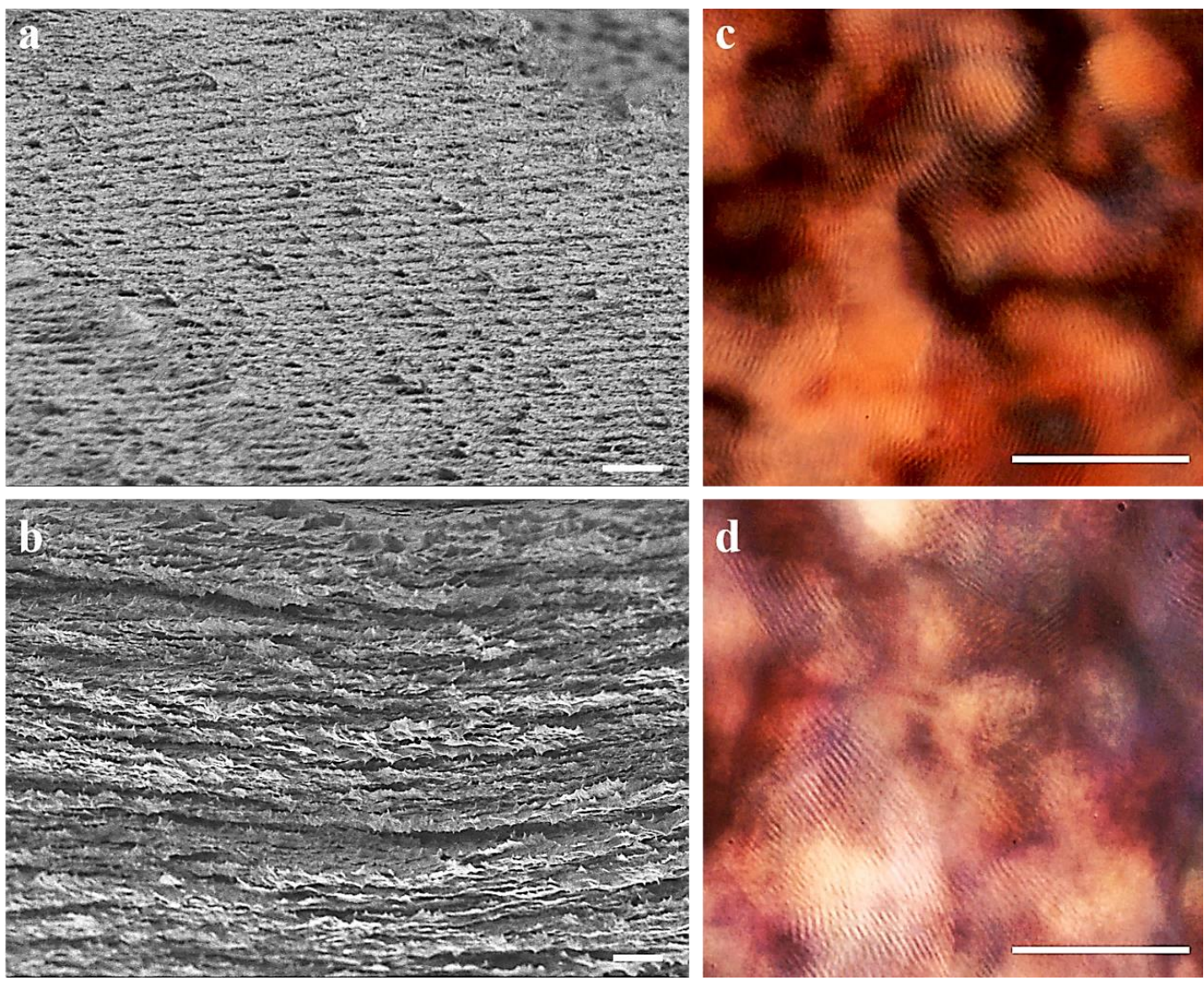

Fig. S3 SEM images of $\mathrm{CNC} / \mathrm{TiO}_{2}$ hybrid films: (a) weight ratio=1 (scale bar $\left.=1 \mu \mathrm{m}\right)$, (b) weight ratio $=2(\mathrm{scale}$ bar $=$ $4 \mu \mathrm{m}$ ). POM images of $\mathrm{CNC} / \mathrm{TiO}_{2}$ hybrid films: (c) weight ratio=1, (d) weight ratio=2 (scale bar $=50 \mu \mathrm{m}$ ).

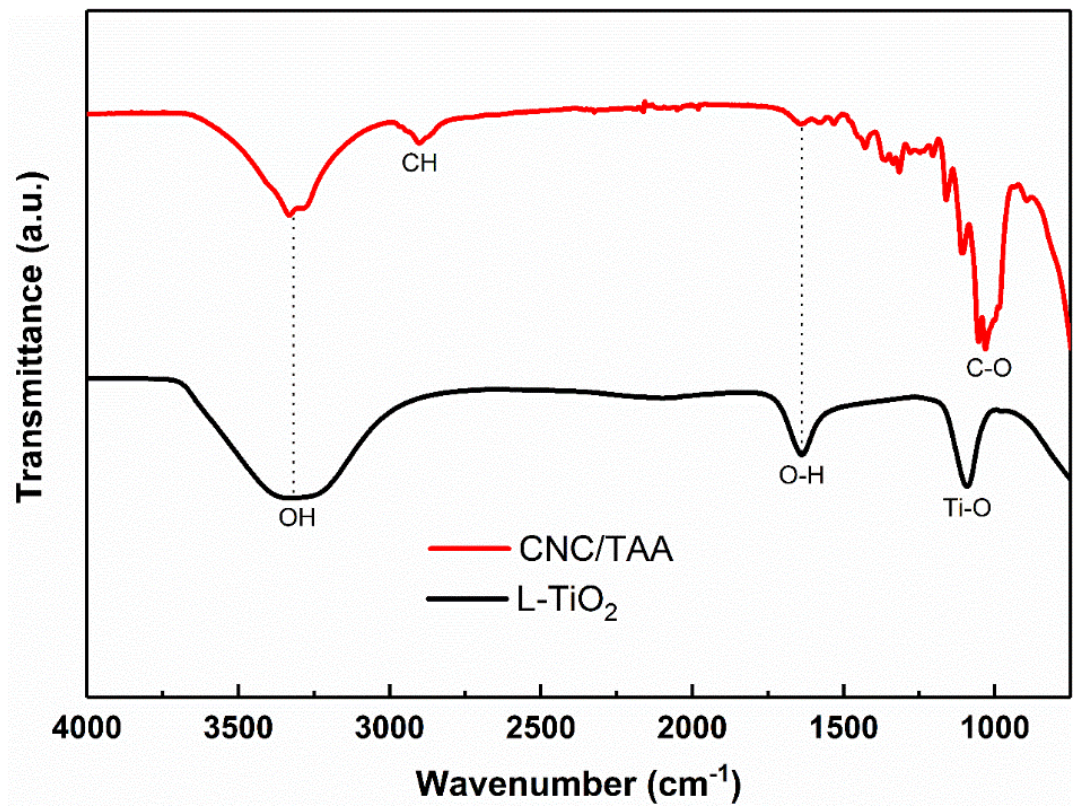

Fig. S4 FT-IR spectra of $\mathrm{CNC} / \mathrm{TiO}_{2}$ hybrid film and $\mathrm{L}^{-\mathrm{TiO}_{2}}$ film. 

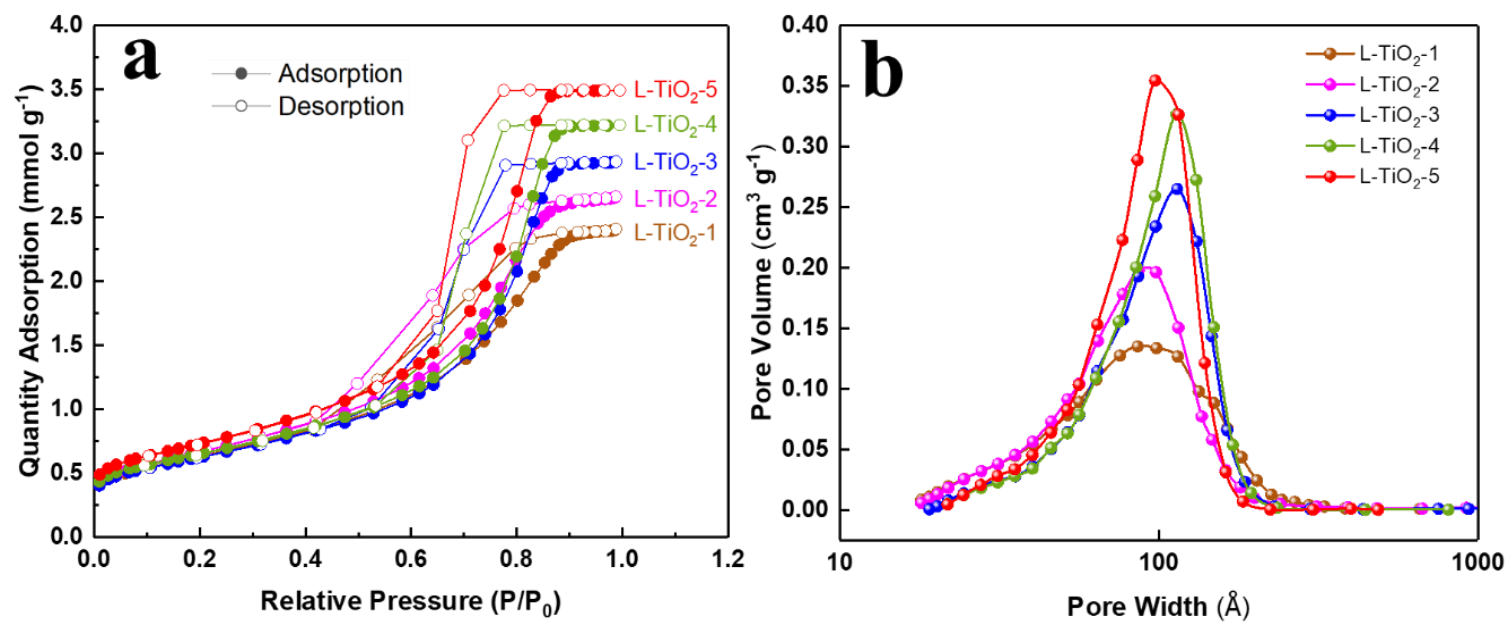

Fig. S5 (a) adsorption/desorption isotherms for nitrogen in $\mathrm{L}_{-} \mathrm{TiO}_{2}$ films. (b) $\mathrm{BJH}$ pore sized distributions for $\mathrm{L}^{-\mathrm{TiO}}{ }_{2}$ films.
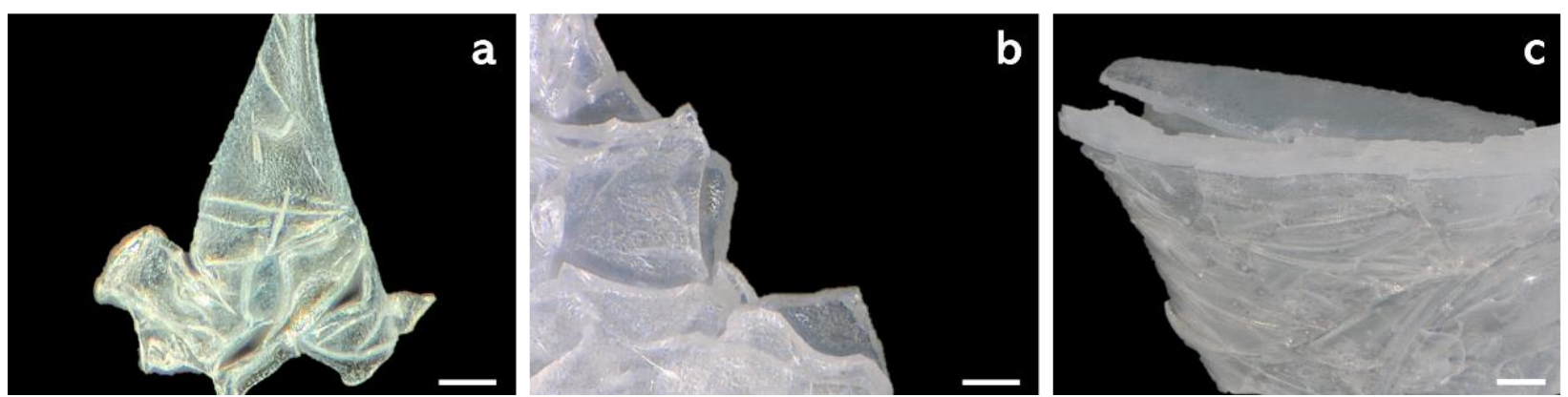

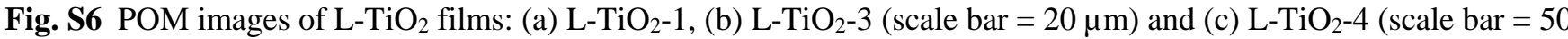
$\mu \mathrm{m})$.
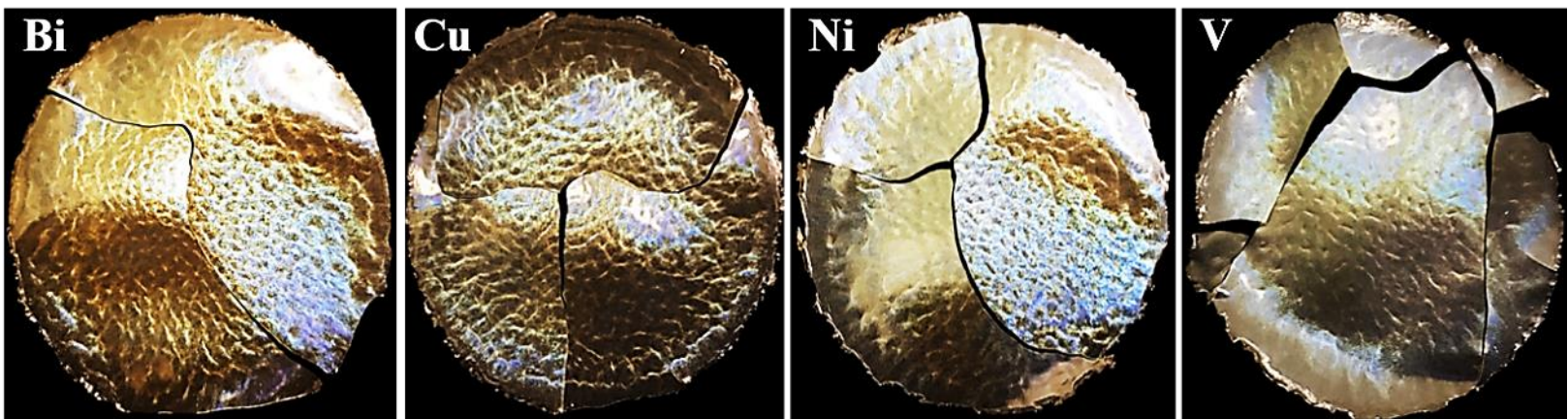

Fig. S7 Photographs of CNC/loaded metal oxide hybrid films. 

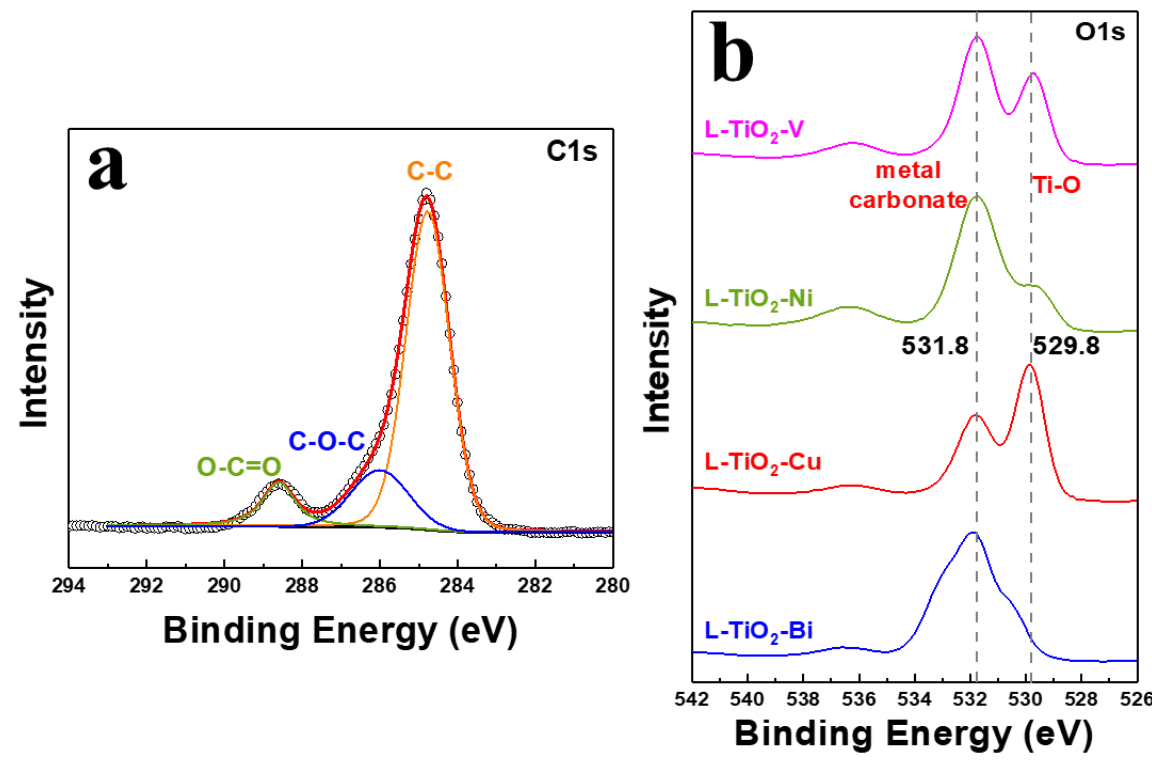

Fig. S8 XPS spectrum of (a) C1s and (b) O1s of different loaded metal oxides.

The general XPS spectra of the surface of the films show detection of carbon and oxygen elements (Fig. S9). The residual carbon (C1s peak), remaining from the decomposition of the TAA precursor or due to contamination during the XPS analysis, is observed at $284.8 \mathrm{eV}$ for all the samples(Fig. S9a) ${ }^{[3]}$ The presence of oxygen involves in Ti-O bonds and the metal carbonate species in $\mathrm{TiO}_{2}$ are confirmed by the main peak at 529.8 and $531.8 \mathrm{eV}$. The $\mathrm{O} 1 \mathrm{~s}$ region presents in could be deconvoluted to several peaks. Another peak can be assigned to oxygen involved in the $\mathrm{O}-\mathrm{H}$ bonds in the hydroxyl groups $/ \mathrm{H}_{2} \mathrm{O}$ or $\mathrm{C}-\mathrm{O}$ (Fig. S9b).
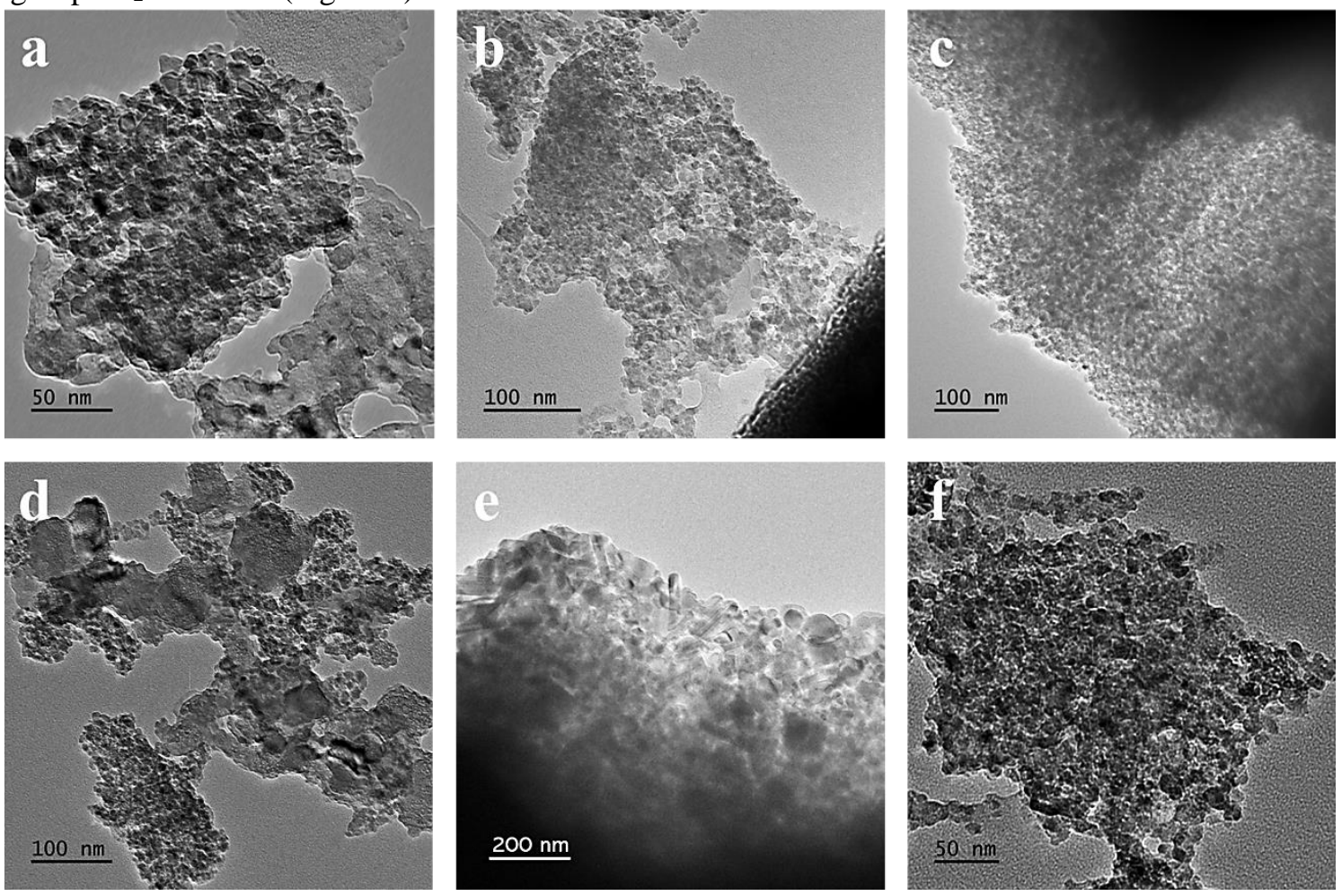

Fig. S9 The TEM characterization of (a,b) lamellar $\mathrm{TiO}_{2}$, (c) $\mathrm{TiO}_{2} / \mathrm{Cu}$, (d) $\mathrm{TiO}_{2} / \mathrm{Ni}$, (e) $\mathrm{TiO}_{2} / \mathrm{Bi}$ and (f) $\mathrm{TiO}_{2} / \mathrm{V}$. 


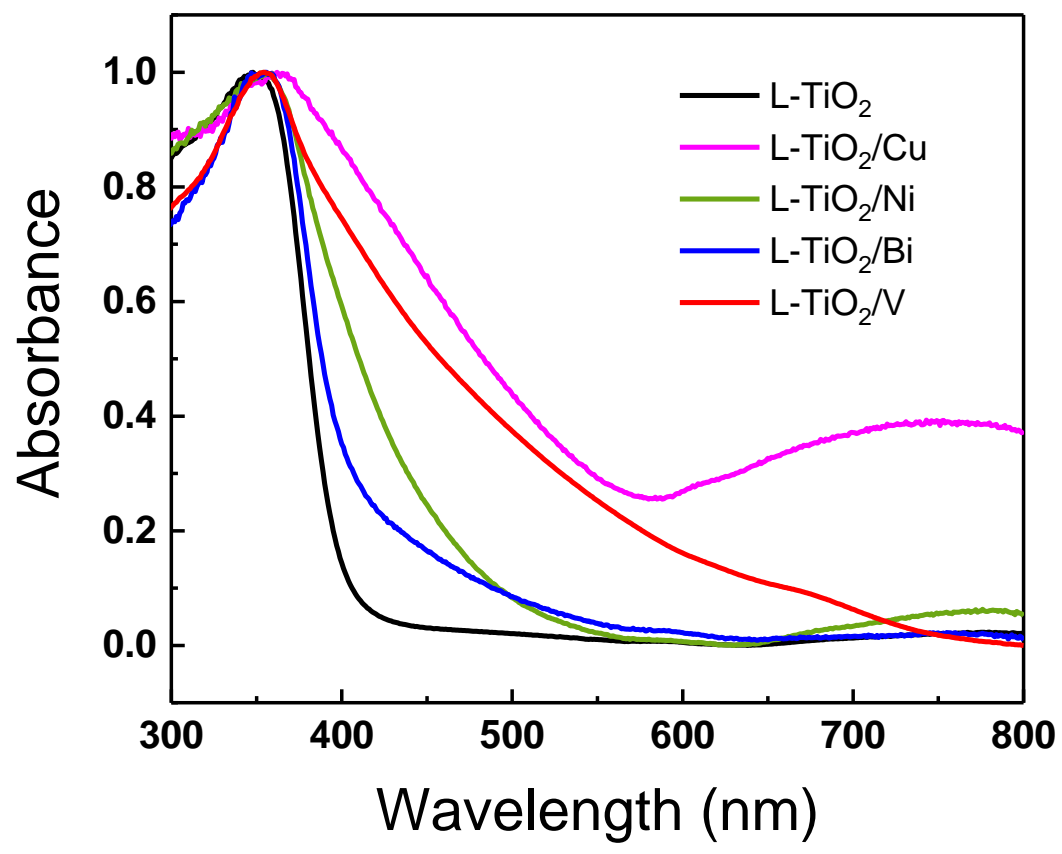

Fig. S10 UV-Vis spectra of metal oxide mixed $\mathrm{TiO}_{2}$ with lamellar structure.

\section{Table S1-S2}

Table S1. Compositions and properties of $\mathrm{CNC} / \mathrm{TiO}_{2}$ hybrid films.

\begin{tabular}{|c|c|c|c|c|c|c|}
\hline Sample name & $\begin{array}{l}\mathrm{TAA}(\mathrm{g}) / 10 \\
\operatorname{mL} \mathrm{CNC}(\mathrm{g})\end{array}$ & $\begin{array}{l}\text { Wt. } \% \\
\text { CNC }\end{array}$ & $\begin{array}{l}\lambda_{\max } \\
(\mathrm{nm})\end{array}$ & $\begin{array}{l}\text { Puv-Vis } \\
(\mathrm{nm})^{[\mathrm{a}]}\end{array}$ & $\begin{array}{l}\text { PSEM } \\
(\mathrm{nm})\end{array}$ & $\begin{array}{l}\text { Calcined } \\
\text { films }\end{array}$ \\
\hline $\mathrm{CNC}$ & 0 & 100 & 288 & 166 & -- & -- \\
\hline CNC/TAA-1 & 0.5 & 66.7 & 438 & 258 & 197 & $\mathrm{~L}-\mathrm{TiO}_{2}-1$ \\
\hline CNC/TAA-2 & 1 & 50 & 454 & 2667 & 210 & $\mathrm{~L}^{-\mathrm{TiO}_{2}-2}$ \\
\hline CNC/TAA-3 & 1.5 & 40 & 475 & 279 & 241 & $\mathrm{~L}^{-\mathrm{TiO}_{2}-3}$ \\
\hline CNC/TAA-4 & 2 & 33.3 & 501 & 295 & 274 & $\mathrm{~L}^{-\mathrm{TiO}_{2}-4}$ \\
\hline CNC/TAA-5 & 2.5 & 28.6 & 540 & 318 & 302 & $\mathrm{~L}_{-} \mathrm{TiO}_{2}-5$ \\
\hline
\end{tabular}

[a] The average refractive index was assumed to be 1.7 for all hybrid films. 
Table S2. Surface area, pore diameter, and pore volume of $\mathrm{L}^{-\mathrm{TiO}_{2}}$ films.

\begin{tabular}{llll}
\hline $\begin{array}{l}\text { Sample } \\
\text { name }\end{array}$ & BET Surface Area $\left(\mathrm{m}^{2} / \mathrm{g}\right)$ & $\begin{array}{l}\text { BJH Pore Diameter } \\
(\mathrm{nm})^{[\mathrm{b}]}\end{array}$ & $\begin{array}{l}\text { Pore Volume } \\
\left(\mathrm{cm}^{3} / \mathrm{g}\right)\end{array}$ \\
\hline${\mathrm{L}-\mathrm{TiO}_{2}-1}^{2}$ & 72.57 & 8.58 & 0.14 \\
$\mathrm{~L}-\mathrm{TiO}_{2}-2$ & 71.83 & 8.65 & 0.20 \\
${\mathrm{~L}-\mathrm{TiO}_{2}-3}^{71.67}$ & 11.43 & 0.27 \\
${\mathrm{~L}-\mathrm{TiO}_{2}-4}^{2}$ & 70.99 & 11.37 & 0.33 \\
$\mathrm{~L}^{-\mathrm{TiO}_{2}-5}$ & 64.53 & 9.76 & 0.35 \\
\hline
\end{tabular}

[b] Determined by the adsorption branch of the $\mathrm{N}_{2}$ isotherm at $77 \mathrm{~K}$.

\section{References}

[1] M. S. Amara, E. Paineau, S. Rouzière, B. Guiose, M. E. M. Krapf, O. Taché, P. Launois, A. Thill, Chem. Mater. 2015, 27, 1488-1494.

[2] M. Kunst, C. Colbeau-Justin, D. Huguenin, J. Mater. Sci. 2003, 38, 2429-2437.

[3] M. N. Ghazzal, R. Wojcieszak, G. Raj, E. M. Gaigneaux, Beilstein. J. Nanotech. 2014, 5, 68-76. 